HID 41 (2014)

\title{
APORTACIÓN AL ESTUDIO DE LA HACIENDA DEL CONCEJO DE CÓRDOBA A FINES DE LA EDAD MEDIA ${ }^{1}$
}

\section{CONTRIBUTION TO THE STUDY OF THE PUBLIC FINANCE COUNCIL OF CORDOBA AT THE END OF THE MIDDLE AGES}

\author{
JAVIER LÓPEZ RIDER \\ Universidad de Córdoba \\ 152lorij@hotmail.es
}

RESUMEN: Con este estudio se pretende contribuir al conocimiento de la Hacienda del concejo de Córdoba para el periodo bajomedieval. Se desarrolla un detallado análisis de aquellas rentas municipales existentes para esta ciudad, clasificándolas según su tipología, almojarifazgo, portazgo, roda, meaja del medir de los paños, multas, aguadores o azacates, bienes inmuebles y raíces, entre otras. Se estudia un impuesto novedoso y casi desconocido hasta el momento, la renta de las velas, recaudada para la iluminación de los vecinos pobres del territorio cordobés. Se detalla cómo el concejo aplicaba todos estos gravámenes en su jurisdicción especificando muchas de sus villas, y finalmente, se plasman las cantidades ingresadas a mediados del siglo $\mathrm{XV}$, contrastando todo ello con otras haciendas municipales de fines de la Edad Media.

Palabras ClaVe: Córdoba, concejo, hacienda, economía, impuestos, ingresos, Baja Edad Media.

ABSTRACT: This study aims to contribute to the knowledge of the public finance council of Córdoba for the late medieval period. It develops a detailed analysis of those existing municipal revenues for the city, classifiying them according their typology; so almojarifazgo, portazgo, roda, measure meaja of cloths, fines, water carriers or azacates, real estate and estate, among others. It studies a new and almost unknown tax so far, the tax of candles, collected for the lighting of the poor people of the territory of Cordoba. It details how the council would apply these assessments in his jurisdiction specifying many of its villages, and finally, it

1. Abreviaturas utilizadas: $\mathrm{ACC}=$ Archivo de la Catedral de Córdoba; $\mathrm{AGS}=$ Archivo General de Simancas; AHPCO = Archivo Histórico Provincial de Córdoba; AMCO = Archivo Municipal de Córdoba; DRAE = Diccionario de la Real Academia Española; Ibid.= Ibidem; LAC = Libro de Acta Capitular; Mrs.= Maravedís; OM = Ordenanzas Municipales; PERG. = Pergamino; PNCO = Sección de Protocolos Notariales de Córdoba; RGS = Registro General del Sello. 
embodies the amounts paid in the mid-fifteenth century, contrasting these aspects with all other municipal estates of the late Middle Ages.

KEY WORDS: Córdoba, council, public finance, economy, taxes, income, Late Middle Ages.

\section{INTRODUCCIÓN}

En la actualidad contamos con multitud de obras y trabajos que estudian y analizan con éxito las haciendas del ámbito castellano. Se conocen las cuentas de numerosos concejos cuya diferencia más trascendental consiste en la dimensión de los ingresos o gastos, en algún que otro impuesto poco conocido o con distinta denominación en unas y otras zonas geográficas. Sin embargo, la falta de bibliografía acerca de esta temática en algunas ciudades es muy notable, sobre todo si nos centramos en la economía andaluza medieval. Este problema surge, como bien señala Antonio Collantes de Terán, de la escasez de fuentes documentales conservadas hasta nuestros días ${ }^{2}$, de forma que los datos sobre finanzas o fiscalidad bajomedieval no son tan boyantes como desearíamos. En algunos casos, según explica María Asenjo González, existen los libros de hacienda o de mayordomía, que proporcionan un importante conocimiento acerca de las haciendas locales existentes en el Medievo ${ }^{3}$.

En este sentido, la historia local de la ciudad de Córdoba es víctima de esa falta de documentación puesto que no se han conservado sus libros de hacienda o mayordomía, y por ende, apenas hay rastro de las cuentas presentadas por el tesorero o mayordomo de la época al concejo. La escasa información que se conoce acerca de su funcionamiento hacendístico aparece de forma muy dispersa y analiza el tema de forma escueta. De este modo, la finalidad del presente trabajo es realizar un estudio pormenorizado de la hacienda concejil de Córdoba, conociendo qué gravámenes existían durante el siglo XV y cómo eran aplicados en todo el territorio, analizando qué rentas proporcionaban mayores ingresos al cabildo cordobés, para poder realizar una valoración aproximada del estado en el que se encontraba la economía cordobesa bajomedieval. En definitiva, se intentará explicar cómo era y en qué condiciones se encontraba la hacienda cordobesa para fines de la Edad Media, creando una evolución histórica que nos ayude a comprender el funcionamiento tanto del concejo como de su hacienda.

Para alcanzar la tarea propuesta dispongo de un documento que, a pesar de no estar transcrito ni estudiado en profundidad, fue recogido a principios de los años ochenta por John Edwards, quien no fue mucho más allá de su lectura ${ }^{4}$. El conteni-

2. A. Collantes de Terán Sánchez. "Ciudades y villas andaluzas: variedad impositiva y diversidad ante el hecho fiscal”, Actas del V Congreso de Estudios Medievales. Finanzas y fiscalidad municipal, León, 1997, pp. 485-506.

3. M Ma Asenjo González. Segovia. La ciudad y su tierra a fines del Medievo, Segovia, 1986, p. 457.

4. J. Edwards. Christian Córdoba. The city and its región in the late Middle Ages, Cambridge, 1982, pp. 196-198. 
do de este legajo trata del pleito que mantuvo el conde de Belalcázar con la ciudad de Córdoba acerca de la dehesa de Madroñiz, entre otras propiedades cercanas. A pesar de datar del siglo XVI, en su interior contiene un inventario de las rentas del concejo cordobés de los años 1452-1453, del cual vamos a servirnos como base principal para la elaboración de este estudio. Pero se completará mediante el uso de otras fuentes documentales, entre las que se encuentran algunas ordenanzas concejiles de la ciudad, que recogen datos de especial interés, las actas capitulares del concejo de Córdoba y documentos procedentes de diferentes secciones del Archivo Municipal de Córdoba.

A lo anterior, habría que añadir las actas capitulares del cabildo catedralicio, consultadas en el Archivo de la Catedral de Córdoba, y documentos procedentes del Archivo General de Simancas, donde se plasma una buena información para la temática que pretendemos abordar. En último lugar, también es fundamental el uso de los protocolos notariales de la ciudad conservados en el Archivo Histórico Provincial de Córdoba, donde se hacen importantes menciones sobre aspectos económicos.

\section{LAS RENTAS DEL CONCEJO DE CÓRDOBA}

Una vez transcurrida la conquista de Andalucía en el siglo XIII y ocupadas las ciudades, los recursos para afrontar los gastos solían proceder de las arcas de la Corona o de los repartos vecinales ${ }^{5}$. Sin embargo, alcanzados los siglos bajomedievales, los concejos fueron asumiendo mayores responsabilidades en la gestión de los recursos mínimos que garantizaban su subsistencia. Con este fin, cada uno de ellos poseía unos determinados oficiales que se encargaban de llevar a cabo las recaudaciones pertinentes. En función de la ciudad o el concejo que se estudie, se obtendrán una gran variedad de rentas que pueden o no coincidir con las documentadas en las restantes regiones peninsulares; además, variarán enormemente las cifras de ingresos, que en unos casos pueden ser positivos y formidables, o por el contrario, desfavorables con unos déficits en ocasiones bastantes intensos.

La ciudad de Córdoba, al menos para los años de 1452-1453, no poseía unas arcas muy ricas según evidencia la documentación consultada. No obstante, el déficit que sufría era minoritario en comparación con otras ciudades de la Corona castellana. Antes de entrar en detalle en el análisis de las rentas que poseía el concejo cordobés para mediados del siglo $\mathrm{XV}$, hay que tener en consideración la diversidad y la desigual importancia de cada una de ellas, pues en los documentos examinados tenemos mención a almojarifazgos, rodas, tierras, dehesas, hierbas, censos sobre construcciones hidráulicas e industriales, velas para la iluminación, multas impuestas por los oficiales concejiles encargados del sector hacendístico, entre otras. A lo largo de este trabajo iremos analizando cada impuesto minucio-

5. A. Collantes de Terán Sánchez. "Ciudades y fiscalidad", VI Coloquio Internacional de Historia Medieval de Andalucía. Las ciudades andaluzas (Siglos XIII-XVI), Málaga, 1991, pp. 129-149. 
samente, conociendo de qué gravamen se trataba, sobre qué era aplicado, y qué cuantía económica proporcionaba a las arcas del concejo de Córdoba.

\subsection{Los ingresos de la hacienda cordobesa}

\subsubsection{Impuestos indirectos: transacciones comerciales y de circulación}

De todos los ingresos que aportaban un cierto beneficio económico para Córdoba, habría que centrarse en primer lugar, en aquellos que podemos denominar como "impuestos indirectos". Dentro de estos, el almojarifazgo será uno de los más importantes y que mayor ayuda proporcionaba a la hacienda cordobesa. Como ya es sabido, su origen es probablemente islámico pues procede del término almojarife que significa tesorero ${ }^{6}$. Según Abboud Haggar, el vocablo almojarife surge de al-musrif (supervisor) que era el cobrador de las aduanas situadas en las puertas de las ciudades y puertos durante la etapa andalusí 7 . Sin embargo, la palabra almojarifazgo fue acuñada por los castellanos en Toledo, documentándose por vez primera en 1195. No llegará a ser muy utilizada hasta bien avanzada la Reconquista permitiendo que surgieran nuevos almojarifazgos a lo largo de la Meseta Sur, como en Murcia o Andalucía ${ }^{8}$.

El almojarifazgo era un conjunto de rentas que, a finales del siglo XIII, contaba con numerosos censos; existían los que recogían bienes inmuebles pertenecientes a la Corona, normalmente dedicados a actividades mercantiles (molinos, aceñas, hornos, baños, etc...), también sobre derechos de organización del mercado y compraventa de diversos productos, los diezmos, portazgos, y por supuesto aranceles aduaneros, sin olvidar los oficios artesanales (almotaclacía y alaminazgo) ${ }^{9}$. La mayoría de los derechos que tenían los almojarifazgos se fueron perdieron para el tesoro real a partir del siglo XIV, lo que motivó la decisión de los monarcas de ir cediéndolos a las haciendas municipales teniendo como resultado el surgimiento de los almojarifazgos concejiles ${ }^{10}$. Ahora el almojarifazgo designaba aquellos derechos de tránsito que se cobraban sobre las mercancías, casi siempre a la entrada o salida de cualquier núcleo poblacional, y por normal general, este impuesto es encontrado en aquellos lugares en que fueron establecidos anteriormente por los musulmanes ${ }^{11}$. A veces los almojarifazgos cobraron gran importancia en relación

6. M.A. Ladero Quesada. El siglo XV en Castilla, Barcelona, 1982, pp. 23-25.

7. S. Abboud Haggar. "Leyes musulmanas y fiscalidad mudéjar", Actas del V Congreso de Estudios Medievales. Finanzas y fiscalidad municipal, León, 1997, pp. 169-205.

8. M.L. de Castro Antolín. "Consideraciones en torno al origen y concepto del almojarifazgo”, Actas del I Congreso de Historia de Andalucía. Andalucía Medieval, vol. I, Córdoba, 1982, pp. 435-442.

9. M.A. Ladero Quesada. El siglo XV en Castilla, pp. 23-25.

10. J.D. González Arce. "De conjunto de rentas a impuesto aduanero. La transformación del almojarifazgo durante el siglo XIV en el reino de Murcia", Anuario de Estudios Medievales, 42 (2012), pp. 669-696.

11. M.A. Ladero Quesada. La Hacienda real de Castilla en el siglo XV, Madrid, Universidad de la Laguna, 1973, pp. 125-129. 
al sistema de alcabalas en los siglos XIII y XIV. Restos de este fenómeno se observan en los de Córdoba y Sevilla todavía en el siglo XV ${ }^{12}$. Con esta evolución, el almojarifazgo se aplicaba solamente como un impuesto arancelario regulando la actividad comercial en Toledo, Andalucía o Murcia, quedando este nuevo almojarifazgo exento de muchas otras actividades económicas.

De todo lo mencionado, los beneficios más importantes para los centros urbanos de un tamaño considerable procedían del tráfico y de los intercambios comerciales, destacando casos como los de Burgos o Murcia ${ }^{13}$. En la región andaluza, los almojarifazgos de Sevilla y de Córdoba constituyen un caso excepcional puesto que los ingresos que obtenían de este impuesto no solo procedían de las ciudades, como en el resto de concejos castellanos, sino que sus beneficios emanaban directamente de las villas y lugares de sus términos jurisdiccionales. Esta ventaja comenzó con Alfonso X, al otorgar a ambos concejos el almojarifazgo de la tierra, lo que les permitía cobrar derechos de tránsito y primera venta en los lugares de sus alfoces ${ }^{14}$. No obstante, no será hasta 1327 cuando se le entregue a Córdoba el almojarifazgo de sus villas ${ }^{15}$. La documentación anexa a este estudio así lo avala para el caso cordobés, que a mediados del siglo XV contaba con el almojarifazgo de Almodóvar del Río (incluyendo las ventas de Guadarromán y San Andrés), Las Posadas, Peñaflor, Hornachuelos, el Villar, Belmez, Espiel, Fuente Ovejuna, Pedroche, Ovejo, Puente de Alcolea, Adamuz, Algallarín, Pedro Abad, Montoro, Aldea del Río, Bujalance, Castro del Río, Castro el Viejo, Santaella y La Rambla. Todo el alfoz cordobés contribuía en las arcas de la ciudad, incluso más lugares de los que el documento refleja, como son Montilla, Aguilar de la Frontera y Cañete, cuyos almojarifazgos también revertían al concejo ${ }^{16}$.

El almojarifazgo, entendido como impuesto aplicado al tráfico comercial de los pueblos del alfoz cordobés, proporcionaba unos $83.681 \mathrm{mrs}$. anuales. Hay que matizar, que esta cifra de ingresos es francamente difícil conocerla con exactitud. La contrariedad se origina en el instante que se le otorga un valor concreto al ducado, moneda que aparece una sola vez en toda la relación de cuentas de mediados del siglo XV adjuntas a este trabajo, concretamente en el almojarifazgo de Posadas. En este documento le asignan un valor de $811 \mathrm{mrs}$., sin embargo, según otros estudios, en realidad para mediados del siglo XV su valor era de $165 \mathrm{mrs} .{ }^{17}$. Si te-

12. Ibid.

13. A. Collantes de Terán Sánchez y D. Menjot. "Hacienda y fiscalidad concejiles en la corona de Castilla en la Edad Media", Historia. Instituciones. Documentos (en adelante HID), 23 (1996), pp. 213-254.

14. M.A. Ladero Quesada. "Las haciendas concejiles en la corona de Castilla", Actas del V Congreso de Estudios Medievales. Finanzas y fiscalidad municipal, León, 1997, pp. 8-71.

15. A. Collantes de Terán Sánchez. "Ciudades y villas andaluzas: variedad impositiva y diversidad ante el hecho fiscal", p. 488.

16. R.G. Peinado Santaella. "Fiscalidad señorial y tráfico comercial en Andalucía a fines de la Edad Media: Notas para su estudio", Actas del II Coloquio de Historia Medieval Andaluza. Hacienda y comercio, Sevilla, 1981, pp. 133-158.

17. A. Mackay y M.A. Ladero Quesada. Moneda, precios y politica en la Castilla del siglo XV, Universidad de Granada y Universidad de Sevilla, 2006, pp. 182-183. La misma equivalencia de 1 ducado $=165$ mrs. le otorga J.M. de Francisco Olmos. "La moneda de la Castilla bajomedieval. Medio 
nemos en cuenta esto, el almojarifazgo cordobés aportaría a la hacienda cordobesa $80.451 \mathrm{mrs}$. anuales, obteniendo por tanto una diferencia de $3.230 \mathrm{mrs}$. Esto puede tratarse de un error de los oficiales de la época puesto que el ducado alcanza su máximo valor en el reinado de los Reyes Católicos, concretamente en 1497, cuyo precio era de 375 mrs., y por tanto, es improbable que un ducado tenga un valor tan superior en 1452. Siendo fidedignos al documento medieval, tomaremos por válidos los $83.681 \mathrm{mrs}$. a pesar de su posible error.

Habría que señalar que no se contabilizan los ingresos procedentes del Villar, que en los años de 1452 y 1453 no se arrendó, ni de Espiel, Ovejo y Belmez que estaban ocupadas por el maestre de Alcántara. Como puede observarse en el cuadro 1 de los apéndices, Córdoba aumentó durante varios años sus ganancias a través de esta renta y, aún disminuyendo el beneficio a partir de 1482, mantuvo una buena cifra de ingresos para finales del siglo XV. Si bien las cantidades económicas recibidas eran de su tierra, y por ende, de más allá de la ciudad, dentro de ésta se aplicaban unas ordenanzas muy estrictas acerca del almojarifazgo, pues se incluía en su fiscalidad todos los productos que penetraban en Córdoba con objeto de comerciar con ellos; sin embargo, siempre y cuando los vecinos de la población declarasen que esas mercancías eran para uso personal no pagaban nada por ellas ${ }^{18}$.

En 1455 el tráfico comercial cordobés se realizaba por las puertas del Puente, de Sevilla, del Rincón y de Plasencia ${ }^{19}$; en alguna de ellas se situaba la casa de la Aduana, donde los almojarifes nombraban a sus oficiales para que se encargaran de cobrar el dinero y llevar un cierto control. En este edificio se llevaba a cabo una rígida atención sobre las recaudaciones de este impuesto indirecto. Según Escobar Camacho, la Aduana se situaría cerca de la Puerta del Puente Mayor de Córdoba, concretamente en la zona sur de la collación de Santa María y sería partícipe de una red viaria (calle Mayor) de gran importancia desde un punto de vista comercial, prolongándose desde la Puerta del Puente a la Puerta de la Pescadería (actuales calles Corregidor Luis de la Cerda y Cardenal González). Se trataría, sin duda, de una entrada muy concurrida al ser de obligado paso para las personas que penetraban a través del puente en la ciudad. La casa de la Aduana se situaba en la acera meridional del tramo de la calle anteriormente citada que iba desde la Puerta del Puente hasta la calleja del Caño Quebrado, detrás de la Catedral (actual calle Corregidor Luis de la Cerda).

Junto a esta casa existía otra que actuaba como prisión para los deudores del almojarifazgo ${ }^{20}$. Hay constancia de oficiales que trabajaban para este impuesto; en 1443 Antón Sánchez cobró 500 mrs. por haber estado en la aduana recaudando

de propaganda e instrumento económico", II Jornadas cientificas sobre documentación de la Corona de Castilla (siglos XIII-XV), Madrid, 2003, p. 327.

18. M.A. Ladero Quesada. La hacienda real de Castilla en el siglo XV, pp. 125-129.

19. J. Edwards. Christian Córdoba. The city and its región in the late Middle Ages, p. 81.

20. J.M. Escobar Camacho. "Economía urbana de Córdoba durante la época de los RR.CC", en Córdoba y la época de Isabel la Católica, Córdoba: Real Academia de Córdoba de Ciencias, Bellas Letras y Nobles Artes, 2006, pp. 193-216. 
el diezmo del almojarifazgo para la catedral de Córdoba ${ }^{21}$ y en 1457 se recoge que Ferrand Gutiérrez era almojarife ${ }^{22}$. En 1455 Gonzalo Rodríguez de Baeza, arrendador del diezmo del almojarifazgo, recibió la llave del arca que estaba en la Aduana del almojarifazgo bajo la tutela del mayordomo Pedro de Torres ${ }^{23}$, y en 1463 se indica que Ferrand Gómez era alcalde de la aduana ${ }^{24}$.

Solamente ganados y mercancías de transeúntes (descaminados) estaban exentos de cumplir a rajatabla esta tasa. El almojarifazgo de Sevilla era también enormemente importante para la ciudad y basta con consultar los trabajos de González Arce para comprobarlo ${ }^{25}$. Este concejo también pagó almojarifazgo por el tráfico fluvial, donde de hecho se aplicaba la normativa de que se descargasen en los muelles de Córdoba las mercancías siempre y cuando los arrendadores o los respectivos oficiales estuvieren allí presentes. Se enviaban hasta 2.000 pinos anuales para Sevilla puesto que sufrían una gran escasez de madera en esta ciudad ${ }^{26}$ a pesar de la disponibilidad de pequeños puertos como los de Lebrija, Gelves y Palomares. Entre Sevilla y Córdoba estaban ubicados los embarcaderos de El Aguilarejo, Cortijo Rubio, La Rinconada, Palma, Peñaflor, Lora, Cantillana, Brenes, Guadajoz, Alcolea y Villanueva ${ }^{27}$. Incluso se tiene constancia de que los denominados barqueros de Córdoba, documentados desde el siglo XIII, eran los que realizaban el tráfico comercial a lo largo del Guadalquivir. Formaban un conjunto de 40 transportistas como máximo para el siglo XV, debieron ser un grupo comercial bastante potente puesto que presionaban siempre para obtener beneficios, ya sea de cara a pagar menos rentas o gozar de un tráfico fluvial menos controlado. En Córdoba existió el mesón de los Barqueros en el barrio de Santa María, en los inicios del siglo XVI, que debería su nombre a los barqueros que pernoctaban allí2 ${ }^{28}$.

El tráfico comercial fluvial también estaba regulado por una serie de rentas que debían ser pagadas, como la veintena o la cuarentena de los troncos al pasar por determinadas presas o términos y limitaciones. Por ejemplo, se debía pagar la veintena del conde de Santisteban del Puerto en Espeluy o la de la Orden de Calatrava, que era cobrada en las aceñas del Cañaveral, cerca de Martos, o la veintena cobrada por Luis Portocarrero, señor de Palma del Río. En la villa del Carpio, su señor cobraba la cuarentena ${ }^{29}$. También se pagaba la alcabala de los pinos, que

21. 1443.10.02, ACC, Actas capitulares, Tomo I, f. 22r.

22. 1457.11.29, ACC, Actas capitulares, Tomo II, f. 141v.

23. 1455.09.19, ACC, Actas capitulares, Tomo II, f. 73r.

24. 1463.02.28, ACC, Actas capitulares, Tomo III, f. 74r.

25. J.D. González Arce. "El almojarifazgo de Sevilla: una renta feudal", VI Coloquio Internacional de Historia Medieval de Andalucía. Las ciudades andaluzas (Siglos XIII-XVI), Málaga, 1991, pp.151-159; "Las rentas del almojarifazgo de Sevilla", Studia Histórica. Historia Medieval, 15 (1997), Salamanca, pp. 209-254. o "Documentos sobre el almojarifazgo de Sevilla (siglos XIII-XIV)", HID, 20 (1993), Sevilla, pp. 165-196.

26. M.A. Ladero Quesada. La hacienda real de Castilla en el siglo XV, pp. 125-129.

27. R. Córdoba de la Llave. "Navegación y transporte fluvial en la Península Ibérica a fines de la Edad Media", en M. Criado de Val (Coord.), actas del III Congreso Internacional de Caminería Hispánica, Madrid, Aache Ediciones, 1997, pp. 215-233.

28. Ibid.

29. Ibid. 
consistían en entregar ciertas cantidades de pinos en un tiempo determinado. En Córdoba se ha documentado esta renta en 1503, en el mesón de Alfonso de Carmona, donde Pedro Román, vecino de Úbeda, y Bartolomé de Castro, arrendador de las tercias y maravedís de la alcabala de pinos de Córdoba y su tierra entre los años de 1502 y 1503 , discuten ciertos pleitos sobre los derechos de pago de los pinos que Pedro Román traía ${ }^{30}$. Y unos años después, en 1506, llegó a la ciudad cordobesa el delegado de las alcabalas de los pinos para cobrar sus derechos de diez al millar de los años de 1504 y $1505^{31}$.

Queda claro que el concejo de Córdoba reconocía la importancia que ocasionaba el almojarifazgo de su alfoz, motivo por el cual procedía siempre a paliar todos aquellos conflictos que pudieran ocasionar las villas por descontentos generalizados. En este sentido, para evitar quejas por parte de los vecinos y con el objetivo de seguir obteniendo ingresos, se llevaron a cabo una serie de concesiones muy interesantes. En primer lugar, el 30 de marzo de 1457 se hizo un traslado del privilegio otorgado por Enrique III el 20 de marzo de 1401 permitiendo que los vecinos de su término no paguen almojarifazgo de las bestias de silla que gravaba 1 maravedí de coste por cada bestia de carga que tuvieran ${ }^{32}$. Recordemos que las compraventas de acémilas estaban incluidas dentro del almojarifazgo a través de la llamada "alcabala antigua" de Córdoba, fundamentada en un cinco por ciento sobre el valor de la bestia que se llegara a vender ${ }^{33}$. Cincuenta años después, concretamente el 5 de junio de 1451, Juan II proporcionó un privilegio a las ciudades de Sevilla y Córdoba para que sus habitantes no pagasen almojarifazgo ni portazgo dentro de ambas ciudades sobre los 2.000 pinos anuales que traían. El documento especifica muy bien en qué consistía tal otorgamiento:

\section{(...) los mys almojarifazgos de la dicha cibdad de Córdoua e su obispado destos seys años, que començaron el año de myll e quatroçientos e quarenta e seys años, se contyene una ley, su thenor de la qual es este que se sigue: Otrosy, con condición que sean salvados e que no paguen almojarifazgo ni otro pecho ni tributo alguno por los dos myll pinos que viniesen a las cibdades de Córdoba y Sevilla en los di- chos seys años de los reyes onde yo vengo, fizieron merçed a las dichas cibdades, que fuesen francos de no pagar el dicho almojarifazgo e pechos e otros tributos segund que no lo pagaron en los años pasados fasta aquí (.... $)^{34}$.}

El monarca, teniendo en cuenta una ordenanza anterior, decidió mantener el contenido de la misma para evitar problemas mayores. De este modo, aplica la normativa mandando que esos 2.000 pinos puedan transportase por el río Guadalquivir sin obligación de pagar renta alguna, ni de embargarlos o no dejarlos pasar

30. 1503.03.02, AHPCO, PNCO, 14142P, 15, f. 32r.

31. R. Córdoba de la Llave. "Navegación y transporte fluvial en la Península Ibérica a fines de la Edad Media", pp. 215-233.

32. 1457.03.30, AMCO, C-0001, doc. 0034, f. 1r-v.

33. M.A. Ladero Quesada. La hacienda real de Castilla en el siglo XV, pp. 125-129.

34. 1494.02.24, AMCO, C-0001, doc. 0036, f. 1v. 
en caso de que no se abonara la cantidad exigida. El legajo recoge fidedignamente la disposición del soberano:

segund e por la vya e forma e manera que en ella se contyene e encompliendo, dejades e consyntades pasar los dichos dos myll pynos que se acostunbraban levar para las dichas cibdades en cada año por el dicho río Guadalquivyr, por todas las dichas cibdades e vyllas e lugares e términos por donde pasa el dicho ryo (...) les no demandéys ni pidades el dicho almojarifazgo ni otro tributo alguno (... $)^{35}$.

Además del almojarifazgo, que controlaba el mercado, existían otros impuestos indirectos que permitían a los concejos castellanos alimentar sus arcas, como son los portazgos, rodas, castillerías, pontazgos o barcajes que regulaban la circulación de personas, animales y mercancías de cualquier ciudad. La mayoría de estos impuestos indirectos ya eran utilizados desde el siglo XIII como realidad tributaria en los concejos ${ }^{36}$, de manera que con el transcurrir del tiempo fueron proporcionando mayores beneficios económicos, dando como resultado un incremento y una mayor implantación en diferentes sectores: agricultura, ganadería, comercio, comunidades étnico-religiosas, penas impuestas por la sección de justicia, entre otras ${ }^{37}$.

Dentro del grupo de impuestos de circulación, se destaca en primer lugar el portazgo, cuyas características, como bien indica González Mínguez, son difíciles de conocer ya que en la mayoría de los casos muchos impuestos se encuentran dentro de otros o con unas tipologías muy similares, como ocurre con casi todos los impuestos indirectos medievales ${ }^{38}$. A pesar de ello, el portazgo puede ser entendido como el pago que se realizaba para conseguir el derecho de paso por un lugar determinado, ya sea de un camino o una entrada en alguna ciudad o villa. Gravaba la circulación de animales, personas y mercancías. A pesar de que en el documento anexo a este trabajo no se mencione para Córdoba, hay documentación que avala su cobro en beneficio de la hacienda del concejo, pues al igual que en el caso de Sevilla proporcionaba mayor enriquecimiento en los lugares de su "tierra" 39 . En 1491 se documenta un acuerdo realizado entre Pedro de Espinar y Juan de Arévalo, carreteros y vecinos de Córdoba, y Aino de Marín, mercader genovés estante en Córdoba, para traerle desde la ciudad de Jerez de la Frontera hasta Córdoba con doce carretas, 60 arrobas de pastel a 700 mrs. cada carretada, dejándose bien claro que se paguen los portazgos e impuestos que fuesen necesarios por parte del mercader italiano, y por ello recibieron por adelantado $3.810 \mathrm{mrs}^{40}$.

35. Ibid., f. 2r.

36. M.A. Ladero Quesada. "Las haciendas concejiles en la corona de Castilla", p. 21.

37. J.A. Bonachía Hernando. "El concejo como señorío (Castilla, siglos XIII-XV)", Actas del II Congreso de Estudios Medievales. Concejos y ciudades en la Edad Media hispánica, Móstoles, 1990, pp. 429-463.

38. C. González Mínguez. El portazgo en la Edad Media Aproximación a su estudio en la corona de Castilla, Universidad del País Vasco, 1989, pp. 93-105.

39. A. Collantes de Terán Sánchez. "Ciudades y fiscalidad”, p. 136.

40. 1501.04.28., AHPCO, PNCO, 13671P, f. 188v. 
Más importantes son los datos proporcionados por una real provisión de 1492, donde los Reyes Católicos reciben una serie de quejas de ciertos lugares de su alfoz por el pago tan costoso que debían realizar. Gracias a esta disposición, veremos cómo Córdoba pudo diferenciar el portazgo del almojarifazgo ${ }^{41}$. En Andalucía también existen referencias del cobro del portazgo en Jaén, sin embargo como ya se explicó para el almojarifazgo, exceptuando a Sevilla y Córdoba que gozaban de su "tierra", el resto de las ciudades castellanas aplicaban las rentas casi exclusivamente al ámbito de la ciudad y mucho menos en sus villas. En este sentido, Sevilla es la única ciudad andaluza que cobraba los portazgos y las rodas como rentas independientes, a diferencia del resto de los concejos castellanos que dentro de sus almojarifazgos incluían los demás impuestos ${ }^{42}$. De hecho, en muchas ocasiones el portazgo seguía inserto en el almojarifazgo, como por ejemplo en Murcia o Toledo ${ }^{43}$. En el caso de Córdoba, será a través de la citada real provisión de 1492 cuando se consiga convertir el portazgo en una renta específica e independiente del almojarifazgo, como ya se venía haciendo en Sevilla.

En el pergamino consultado se recogen las ocho villas que exigían esa licencia y la denuncia generalizada de todas ellas por el alto precio que pagaban, se trataba de Adamuz, Fuente Obejuna, Aldea del Río (actual Villa del Río), Pedroche, La Rambla, Castro del Río, Santaella y Montoro, reflejándose lo siguiente:

(...) muy noble cibdad de Córdoua e a vos los concejos, alcaldes, alguaziles, regidores, caualleros, escuderos, ofiçiales e omes buenos de las villas de Adamuz e Fuente Ovejuna e Aldea del Río e Pedroche e La Ranbla e Santa ella e Montoro (...) que los dichos portazgos se cojían e llevavan por los arendadores e cojedores que los arrendavan e cojían syn alanzel justo, e que llevavan derechos demasiados e desaforadamente, pedian e llevavan grandes contías de maravedis a los mercaderes e caminantes asy de las cosas que devian pagar portazgo como de las cosas que no lo deuían llevar (... $)^{44}$.

Para controlar ese gasto tan excesivo, entre las diferentes medidas que la Corona implantó, destaca aquella que obliga a cada villa poseer en su término la llamada casa de los portazgos e no otro nonbre con el fin de que todos los pagos y trámites se hagan en este nuevo edificio ${ }^{45}$. En este sentido, aquellos mercaderes,

41. Para conocer en detalle los numerosos productos que circulaban en el comercio ordinario cordobés bajomedieval consultar M. González Jiménez. "Aranceles cordobeses de portazgo. Aportación al vocabulario del comercio medieval”, en M. González Jiménez. A través de Sevilla y Andalucía. Estampas de historia medieval, Universidad de Sevilla, 2011, pp. 113-125.

42. Ibid.

43. J.D. González Arce. "La política fiscal de Alfonso X en el reino de Murcia: portazgos y diezmos", Studia histórica. Historia Medieval, 10 (1992), pp. 73-100.

44. 1492.06.02, AMCO, perg. 113, f. 1r.

45. Ibid., f. 5r. En este folio se incluye la villa de Almodóvar del Río inmediatamente después de la de Montoro, algo que no ocurre a la hora de enumerar las villas afectadas al principio del propio legajo: "Otrosy, que aya casa señalada en las dichas villas de Adamus e Fuente Ovejuna e Aldea del Rio e Pedroche e de La Ranbla e Castro el Rio e de Santa ella e de Montoro e de Almodóvar e en cada vna dellas, la qual se llame la casa de los portazgos e no otro nombre, donde vayan los mercaderes e arieros e otras personas que pasaren con las dichas mercadurias e paguen los dichos portazgos suso 
arrieros o cualquier persona que transportase productos comerciales, estaban forzados a pasar por alguna de estas casas para realizar su correspondiente pago. Una vez hecha esta transacción, el oficial que residía en estas nuevas casas, es decir, el portazguero, entregaba gratuitamente un albalá para que los comerciantes pudieran demostrar haber hecho su desembolso de manera que no era necesario volver a efectuarlo en los demás lugares por los que habían de circular. Igualmente el albalá recogía los productos por los que se había pagado una cuantía determinada. De este modo, cualquier persona que pagara el derecho de portazgo en una de las villas mencionadas no debía pagarlo más en todo el territorio cordobés, siempre y cuando mostrara el mencionado albalá entregado por los oficiales, consiguiéndose así que la renta se abonara una única vez por persona ${ }^{46}$.

También se especifica en el documento que el lugar habilitado para el cobro del portazgo debía estar a media legua alrededor de cada villa. Teniendo en cuenta todo lo anterior, podemos deducir que las denominadas casas de los portazgos estaban situadas extramuros de las villas señaladas, a una distancia como máximo de entre 2 y $3 \mathrm{~km}$. aproximadamente ${ }^{47}$. Este nuevo sistema de recaudación del impuesto municipal del portazgo era mucho más eficaz puesto que la corta lejanía que existía entre los puntos de control respecto a los núcleos de población permitía controlar los impagos, fraudes o abusos, de ahí que se prohíba a los portazgueros colocar guardas de campo, solo les era permitido para los denominados ganados merchaniegos que eran aquellos que se llevaban a vender en ferias y mercados ${ }^{48}$. Según J. Klein, era animales destinados a la venta en los mercados de los pueblos, y por ende, sujetos a portazgos o impuestos locales ${ }^{49}$. En esta real provisión también dejaron constancia de la antigüedad de las normas a cumplir, llegando a plasmar que la política reguladora del portazgo procedía de mucho tiempo atrás, y será Enrique IV quien decidió imponer penas en caso de que no se cumpliese lo que dictaban las disposiciones reales emitidas acerca de la renta ${ }^{50}$.

declarados (...) para coger el dicho portazgo e que allí se coja e no en otra parte alguna, e pida alualá al portadguero por que no pague en otro lugar e que por el alualá no pague cosa alguna, e que diga el alualá de qué cosas pagó e que no lo detenga por el alualá".

46. Ibid., f. 6r. "Otrosi, mandamos que los dichos derechos de portazgo de suso nonbrados e declarados no se lleuen de las mercadurias e otras cosas que fa e here de la dicha cibdad de cordoua, o vinyere a ella saluo de lo travesio, e qual que vna vez oviere pagado en qual quier de las dichas villas de suso nombradas, no lo pague ni le sea demandado ni leuado otra vez, avnque pase por todas las dichas villas o por sus términos mostrando alualá del arrendador o fiel o cojedor del tal portazgo de como lo ha pagado vna vez en qual quier de las dichas villas suso declaradas, la qual dicha alualá mandamos que les sea dada syn les llevar ni demandar derecho alguno por ello, por manera que en toda la tierra de la dicha cibdad no se pague más de vna vez el dicho portazgo".

47. Esta distancia se ha calculado entendiendo que una legua se sitúa entre los 4 y $7 \mathrm{~km}$.

48. 1492.06.02, AMCO, perg. 113, f. 5r.

49. J. Klein. La Mesta. Estudio de la historia económica española, 1273-1836, Madrid, 1990, p. 447.

50. 1492.06.02, AMCO, perg. 113, f. 5v. "Otrosy, mandamos que de aquí adelante para siempre jamás, no aya descaminados ni personas algunas pierdan sus mercadurias ni ganados ni otras cosas por las no manifestar ni pagar el portazgo ni roda más en el lugar de la pena (...) e aya lugar la pena del quarto tanto, segund lo dispone la ley fecha por el señor rey don Enrique, nuestro hermano, en la corte de Córdoua el año de cinquenta e cinco años". 
En último lugar, cabe señalar una peculiar obligación impuesta a las villas cordobesas ya citadas. Además de la casa de los portazgos debían construir unos pilares en los caminos de manera que pudieran limitar la jurisdicción de cada una de ellas, de este modo cada casa de portazgos y sus respectivos portazgueros conocían fácilmente hasta donde alcanzaba su término. Por tanto, cada villa poseía su casa de portazgos con sus límites o pilares respecto a otra población, controlando que si algún individuo transitaba por esas señales y no pagaba fuese penalizado. Lógicamente existían zonas que estaban fuera del alcance de estos nuevos límites, y en estos casos las personas no estaban obligadas a pagar ninguna renta. No obstante, como veremos más adelante, las rodas también estaban situadas cerca de estas casas de portazgos, por lo que prácticamente no existían áreas que escapasen de esta red fiscal. Finalmente como recomendación, se pedía a cada villa que pregonasen anualmente en sus plazas públicas estos límites, con el objetivo de evitar que los vecinos de todo el territorio cordobés desconocieran estas nuevas medidas, justificando en muchas ocasiones sus impagos por ignorancia de las mismas ${ }^{51}$.

Definitivamente, se ha podido comprobar cómo la ciudad de Córdoba obtuvo el privilegio de diferenciar el portazgo como un impuesto municipal independiente e indirecto, recordemos que antes formaba parte del almojarifazgo. Además, gracias a esa transformación en una renta autónoma, el concejo cordobés se ha visto en la necesidad de regular el portazgo en todo su alfoz a través de normas muy llamativas como la creación de las casas de portazgos y pilares en muchas de las villas de su jurisdicción.

A través de la documentación del Registro General del Sello se puede evidenciar que el portazgo cordobés estaba presente en más villas de las señaladas en la real provisión. En unos meses anteriores a la aprobación de esta, algunas poblaciones seguían insertando el portazgo dentro del almojarifazgo, es el caso de Espejo y Lucena ${ }^{52}$, El Carpio ${ }^{53}$ o en el territorio de Santa Eufemia, propiedad de Gonzalo Mejía ${ }^{54}$. Otras villas aparecen únicamente con el portazgo, como por ejemplo Belalcázar e Hinojosa, cuyo arancel le fue mandado al conde de Belalcázar Alfonso de Sotomayor ${ }^{55}$; también en la villa de Luque $^{56}$, perteneciente al señor Egas Venegas, el cual pidió comprobar que se cumplieron los pagos de esta renta en años anteriores; en Baena, donde el arancel del portazgo inserto recoge productos como frisas, paños, lienzos, seda, pasta, algodón, papel, lino, aves, fru-

51. Ibid. "Otrosi, que en las dichas villas e en cada vna dellas de suso nonbradas, hagan pilares o lymites fuera dellas donde pasado aquel lugar o límite, los mercaderes o caminantes o arieros con sus mercadurias ge las haser saber a los portadgueros a pagar el portazgo dellas que yncurran en la pena del quatro tanto, e que los dichos pilares o limites, sean bien señalados porque conozcan bien e se pregone públicamente en cada vn año en las dichas villas e cada vna dellas en las plaças públicas dellas, como pasando el dicho lugar o limite que an pagar los dichos derechos yncurran en la pena del quatro tanto e donde no oviere estas señales o limites que non caygan en pena alguna, e questos mismos limites e pilares sean obligados de poner en cada vn camyno de las dichas villas e de cada vna dellas".

52. 1492.05.23, AGS, RGS, f. 397r-v.

53. 1492.03.01, AGS, RGS, f. 245r-v.

54. 1492.02.23, AGS, RGS, f. 231r-v.

55. 1492.05.15, AHN, Sección nobleza, Osuna, C.325, D.46-48.

56. 1490.10.15, AGS, RGS, f. 187r-v. 
ta, tocinos, sardinas, pellejos, madera, agua, caracoles, hierro, herraje, calderas, corambre, sillas, calzado, esparto, cebo, vino, vinagre, jabón o barros, insertando la regulación y el precio de cada uno de estos productos ${ }^{57}$. En Priego de Córdoba, el lugar denominado "Las Cruces" fue objeto de estudio por parte de la Corona para conocer si realmente era sometida al pago de portazgo por Alfonso de Agui$\operatorname{lar}^{58}$. Igualmente sabemos del cobro de esta renta en otras localidades cordobesas a través de una comisión otorgada a Gómez de Gomara para que se desplazara a Aguilar, Montilla, Monturque, Priego, Cañete y el Pontón de Don Gonzalo (actual Puente Genil) para revisar las quejas impuestas por caminantes y mercaderes acerca del enorme desembolso que tenían que abonar al transitar por cada una de las poblaciones señaladas ${ }^{59}$.

Otra de las rentas de circulación aprovechadas por la administración cordobesa era la denominada roda. En ocasiones, al igual que ocurría con el portazgo, es difícil localizarla puesto que en muchos concejos castellanos aparece incluida dentro del almojarifazgo ${ }^{60}$. Desde mucho antes del reinado de Alfonso X se percibía en razón de la custodia y vigilancia de $\operatorname{caminos}^{61}$, al igual que ocurría con la anubda $^{62}$. El origen de este impuesto parece hallarse también en el ámbito andalusí, pues según María Estela González la palabra procede del árabe al-ribat, siendo su singular arrabita y el plural arrobt $t^{63}$. A través de estos términos se designaba a los grupos que vigilaban y defendían la frontera, derivándose de aquí varias palabras, entre ellas robda o arrobda ${ }^{64}$. No obstante, para Klein la ronda o roda era un impuesto de carácter local recaudado para el mantenimiento de una vigilancia nocturna montada (roda) en los arrabales de una población determinada ${ }^{65}$. Sin duda alguna, el significado no es otro que el ya mencionado, es decir, proporcionar cierta vigilancia y seguridad a los caminos, montes o puertos de una zona determinada que se encuentran indefensos. Sin embargo, conforme transcurren los años se fue originando un impuesto que gravaba el derecho al tránsito por el lugar donde existía un puesto estratégico, teniendo como resultado que tanto el acto de vigilancia como el lugar de cobro de ese impuesto adquirieran la misma denomi-

57. 1492.03.31, AGS, RGS, ff. 49r-54r.

58. 1490.09.10, AGS, RGS, f. 44r-v.

59. 1490.07.09, AGS, RGS, f. 336r-v.

60. A. Collantes de Terán Sánchez, "Ciudades y fiscalidad”, p. 136.

61. M.A. Ladero Quesada. El siglo XV en Castilla, p. 17.

62. A. Collantes de Terán Sánchez y D. Menjot. "La génesis de la fiscalidad municipal en Castilla: primeros enfoques", Revista d'Historia Medieval, 7 (1996), Valencia, pp. 53-80.

63. M.E. González. "La anubda y la arrobda de Castilla", Cuadernos de Historia de España, XXXIX-XL (1964), Buenos Aires, pp. 5-42.

64. Según varios autores el vocablo nace de "arrotova, arrobda, rotova o rotoba, ruebda, rolda, rocova". En este sentido, consultar Ma del Pilar Gil García. "Portazgo y almotacenazgo en La Roda de Albacete a fines de la Edad Media", Congreso de Historia del Señorío de Villena, Instituto de Estudios Albacetenses, Albacete, 1987, pp. 219-225; M.E. González. "La anubda y la arrobda en Castilla", pp. 5-42 o J. Torres Fontes. "Puerto de La Losilla: portazgo, torre y arancel", Miscelánea Medieval Murciana, IX (1982), pp. 57-85.

65. J. Klein. La Mesta. Estudio de la historia económica española..., p. 444. 
nación ${ }^{66}$. Por lo tanto, se trata de una renta más a pagar entre las que regulan el tráfico de viandantes con o sin mercancías, algo estrechamente relacionado con los portazgos aduaneros ${ }^{67}$.

La roda estaba implantada en todos los concejos castellanos; así lo tenemos documentado en Cáceres, Albacete, Murcia, Sevilla, Jaén o Badajoz, donde aparece mencionada como robda ${ }^{68}$. En Sevilla se documentan rodas en las villas de El Pedroso, Castil de las Guardas o Castilblanco, siendo a partir de 1480 cuando su cobro se expanda por todo el alfoz hispalense ${ }^{69}$. Por citar un primer ejemplo para Córdoba, destacar el pleito de 1500 entre esta ciudad y el concejo de Cabeza del Buey (Badajoz) y 23 ganaderos que fueron acusados por Diego Fernández Portichuelo, arrendador de Córdoba, sobre la deuda del pago de la roda y el portazgo de 22.000 ovejas y cabras entre los años 1499 y $1500^{70}$.

Para la ciudad de Córdoba no sólo conocemos algunas de las zonas que estaban controladas y custodiadas por rodas, sino que incluso se publicaron unas leyes mínimas para regular su funcionamiento en 1492 y que fueron fruto, al igual que ocurrió con el portazgo, de las numerosas quejas de mercaderes, arrieros o caminantes sobre el pago tan elevado que tenían que efectuar. Muchas de las medidas a cumplir eran semejantes a las anteriormente vistas para el portazgo, como por ejemplo, que cualquier persona que pagara el derecho de roda en un lugar determinado estaría exenta de volver a abonarlo en todo el territorio cordobés mostrando el correspondiente albalá ${ }^{71}$. En Córdoba se aplicó la exención del pago de la roda sobre algunos productos, entre ellos el trigo y la cebada, así como a los vecinos de la ciudad y su obispado quanto es vso e costumbre e son francos de los pagar ${ }^{72}$.

La ubicación del cobro de las rodas no debía estar muy lejana del lugar donde se percibían los portazgos, de forma que entre las casas de portazgos de cada villa se situarían rodas para controlar mejor los caminos. En este sentido, una de las normas consistía en que las personas que debían pagar la roda lo hicieran en el lugar donde aquella estaba o por su término a media legua de distancia, pues no muy lejos se localizarían las casas de portazgos ${ }^{73}$. Gracias a esto se evitaron los impagos de viandantes y se garantizó que los roderos, a través de guardas de campo o por ellos mismos, vigilaran el territorio y no se cometieran abusos. Los roderos estaban forzados a mostrar el arancel de los Reyes Católicos para justificar

66. C. Ayllón Gutiérrez. "Sobre los orígenes medievales de La Roda: a propósito de una reciente reedición bibliográfica", Al-Basit: Revista de Estudios Albatecenses, 37 (1995), pp. 37-44.

67. J.D. González Arce. "La política fiscal de Alfonso X en el reino de Murcia: portazgos y diezmos", pp. 73-100.

68. J. Rodríguez Molina. "Algunos datos sobre la actividad comercial y fiscal en Jaén y Baeza a fines del siglo XV", Actas del II Coloquio de Historia Medieval Andaluza. Hacienda y comercio, Sevilla, 1981, pp. 159-176.

69. MaA. Carmona Ruiz. La ganadería en el reino de Sevilla durante la Baja Edad Media, Diputación de Sevilla, 1998, p. 429.

70. J. Edwards. "El comercio lanero en Córdoba bajo los Reyes Católicos", Actas del I Congreso de Historia de Andalucía. Andalucía Medieval, vol. I, Córdoba, 1982, pp. 423-428.

71. 1492.06.02, AMCO, perg. 132, f. 1r.

72. Ibid., f. $1 \mathrm{v}$.

73. Ibid. 
el pago que tenían que realizar los mercaderes, arrieros o caminantes. Sin duda, la red de vigilancia y de recaudación impuesta fue muy estricta para todo el alfoz de Córdoba permitiendo que el pago realizado fuese lo más justo posible.

En el arancel que estamos analizando solamente se mencionan las rodas de Adamuz, Guadalcabrilla y El Vacar, pero conocemos otras zonas que estaban igualmente controladas por rodas. En las villas de Belalcázar e Hinojosa existen datos que respaldan la ubicación de una roda que afectaba a ambas poblaciones ${ }^{74}$. En la villa de Adamuz, y según un documento fechado en 1495, el calero Cristóbal Díaz arrendó por traspaso a Bartolomé Ruiz, palomero, y a su mujer María Ruiz, la roda de dicha población con las condiciones y posturas que él mismo tenía pactadas y que le había sido rematada por el concejo de Córdoba por tiempo de un año desde San Juan de junio, por renta de $5.000 \mathrm{mrs}^{75}$. A mediados del siglo XIV, Pedro I encargó a su alcalde de corte Gómez Ferrández de Soria que llevara a cabo varias delimitaciones de términos de la ciudad de Córdoba por ciertas usurpaciones que se habían cometido; en esa delimitación de tierras de su alfoz se detalla otra roda existente en un camino que unía la villa de Baena con el castillo de Castro el Viejo, cuya primera mención aparece aludiendo al citado camino fasta los prados del camino de la Roda, para más tarde indicar que actuaba como mojonera e deste mojón que está en la Roda ${ }^{76}$. A través de una real provisión de Enrique IV se conoce la roda que existía en el pago del Cañaveral, en el camino que unía la ciudad de Córdoba y la villa de Andújar, cerca de Aldea del Río ${ }^{77}$; camino que para Santiago Haro, era el de La Aragonesa y la roda sería pagada en las aceñas que la Orden de Calatrava tenía en el vado de Las Puercas ${ }^{78}$.

Igualmente, en 1452 se recoge en el documento anexo a este trabajo la roda del Vacar, establecida sobre el camino que pasaba a los pies cerca del castillo homónimo. El concejo cordobés ingresaba, solo por esta roda, $21.246 \mathrm{mrs}$. y sus arrendadores fueron en 1479, Andrés y Cristóbal Calero, ingresando $5.000 \mathrm{mrs}^{79}$. En 1491 volvemos a tener constancia de esta misma roda, denominada de dos maneras diferentes, una el campo de la roda de Alvacar ${ }^{80}$ y otra como la roda en el campo de Albacar $^{81}$. No obstante, en 1495 se menciona tanto el campo como

74. R.G. Peinado Santaella. "Fiscalidad señorial y tráfico comercial en Andalucía a fines de la Edad Media: Notas para su estudio", pp. 133-158.

75. 1494.08.19, AHPCO, PNCO, 14132P, 12, f. 28v.

76. E. Cabrera Muñoz. "El problema de la tierra en Córdoba a mediados del siglo XIV", Cuadernos de Estudios Medievales, IV-V (1979), pp. 41-71.

77. 1402.12.14, AMCO, C-142, doc. 1, f. 1r.

78. J. Santiago Haro. "Sobre el trayecto de la «Vía Augusta» por los actuales términos de Andújar, Marmolejo y Lopera (Jaén): Una nueva propuesta (II)”, Boletín del Instituto de Estudios Giennenses, 199 (2009), pp. 11-56.

79. 1479.09.28, AMCO, LAC, f. 73r.

80. 1491.12.29, AHPCO, PNCO, 13665P, 22, f. 20r. "Martin Ruiz vende a Juan Alfonso de Valdés, un asiento de colmenar con diez colmenas en el campo de La Roda de Alvacar, que se dice la posada del Peinado, con el agua y montes que le pertenece por precio de $1.000 \mathrm{mrs}$. .".

81. 1491.01.06, AHPCO, PNCO, 14129P, 17, f. 5v. "Miguel Sánchez de Lara, debe dar a Alfonso Rodríguez de Villacarrillo, 600 mrs. y 11 piernas de tijeras que le restó por pagar de toda la renta de la venta que dicen de la huerta, que es cerca la roda en el campo de Albacar, de todo el tiempo que 
la roda del Vacar ejerciendo como linderos uno de otro ${ }^{82}$. Del mismo modo, la toponimia nos indica en la mayoría de los casos dónde existieron estas, un ejemplo de ello es el topónimo "rodas" ubicado en la villa de La Rambla actualmente, en dirección hacia las poblaciones de Montemayor y Montilla.

El deseo de la mayoría de los transeúntes, ya fueran ganaderos, comerciantes o cualquier otro viandante, era siempre el de intentar burlar estos peajes evitando el correspondiente pago. En 1493 se entregó una comisión al juez de términos de Córdoba, a petición de Diego de Comores y Alonso de Armenta, vecinos de la propia ciudad, para que investigara el comportamiento de ciertos ganaderos que, con poco temor de Dios e en daño de sus conçiençias, solían pastar y caminar con sus ganados por zonas poco frecuentadas de manera que no transitando los caminos regulados por estos puntos aduaneros, no estaban obligados a pagar ya no solo la roda, sino tampoco la asadura o el derecho del Guijo ${ }^{83}$. Gonzalo de Herrera y Mateo de Salcedo, vecinos de Córdoba, explicaron a los monarcas que tenían arrendada la renta del paso del Guijo que era de los propios de la ciudad de Córdoba, pero que algunas presonas non le han querydo nin quyeren pagar la dicha renta del paso ${ }^{84}$. A través de un testimonio de 1514 sabemos que, desde el reinado de Sancho IV, la renta de la roda, asadura y pasaje de El Guijo existía en Córdoba. Además, el 4 de mayo de 1386 Juan I formalizó un privilegio real acerca de esta renta para llevarla a la corte ${ }^{85}$. En 1494 tenemos datos del cobro efectuado en el citado lugar, pues Alfonso Ramírez de Baeza, que era arrendador de la renta y pasaje del Guijo en dicho año por 180.057 mrs., en nombre del honrado caballero Bernardino Figueroa (pagador de 90.028,50 mrs., por la mitad de la dicha renta que le tenía traspasada), acordó entregar a Egas Venegas, veinticuatro de Córdoba y recaudador mayor de los maravedís de las rentas pertenecientes a las labores de los muros y puente de Córdoba, los 180.057 mrs. que ambos le debían de la renta de la roda, asadura y el paso del Guijo ${ }^{86}$.

Según se refleja en el documento de 1452, existía en Córdoba otro pasaje, los derechos de Moratilla con el pasaje de ambos los ríos, que llegaba a proporcionar

la tuvo a renta hasta hoy, dándoselo antes de final de marzo so pena del doble, las 11 piernas de tijeras allá en la venta y los dineros en Córdoba".

82. 1495.03.18, AHPCO, PNCO, 14134P, 20, f. 43r. "Martín Ruiz, el Aguado, arrienda a Fernando, hijo de Juan Miguel, una heredad de casa pajiza con una tinaja y un arca, con un pedazo de viña majuelo y encinar, que posee en la sierra, término de Córdoba, en el campo de Albacar, linderos la roda de albacar, la venta de Alfonso Cárcamo y majuelos de Fernando Cortavientos, por tiempo de 3 años y renta anual de $600 \mathrm{mrs} "$.

83. 1493.02.18, AMCO, C-142, doc. 4, f. 1r. “(...) que Alonso de Armenta e Diego de Comores, veçinos desta dicha çibdad, nos fizieron relasçión (...) diciendo que ellos tienen arrendada la roda y asadura e derecho del guijo, que nos ovimos fecho merced a esta dicha çibdad para las lauores della, que dan los dueños de los ganados que vienen apaçentar al obispado de la dicha çibdad, e diz que algunos dueños de los dichos ganados con poco temor de Dios e en daño de sus conçiençias, se atreven a meter ganados por otras partes no acostumbradas a cabsa de furtar el derecho que deven pagar e que sy asy ouiere de pasar, ellos resçibirian mucho agrauio e daño e que la dicha renta se dismynuyría (...)".

84. 1485.02.22, AMCO, C-142, doc. 2, f. $1 \mathrm{r}$.

85. 1514.06.19, AMCO, C-142, doc. 9, f. $1 \mathrm{r}$.

86. 1494.10.02., AHPCO, PNCO, 14132P, 11, f. 1r. 
1.347 mrs. anuales a la economía concejil. Estos pasajes se encuentran con frecuencia en el territorio pues formaban parte de los caminos o rutas terrestres. La mayoría de ellos era de gran utilidad porque ayudaban a unir las orillas de los ríos, salvando el obstáculo del agua en conexión con un puente o un vado cercano o, por el contrario, ante la falta de alguno de estos medios ${ }^{87}$. Fueron de gran utilidad para el transporte de personas y ganado, sobre todo para arrieros, ganaderos, mercaderes o viajeros. Existieron muchos pasajes en Córdoba, por ejemplo en Villa del Río, Adamuz, El Carpio, Posadas, Palma del Río, Alcolea y Villanueva del Río ${ }^{88}$, además de los ya mencionados del Guijo y Moratilla. Más allá del territorio cordobés se han documentado infinidad de ellos, en Lora, Coria, Sevilla, Brenes, Tocina, Talavera, Pina, Malpica o Valdecañas, entre otros lugares ${ }^{89}$.

El desplazamiento de una orilla a otra del curso fluvial se realizaba a través de barcas, documentadas en Castilla la Nueva, Extremadura o Andalucía. También en Málaga, sobre el río Candoncillo; en Jaén, junto a la localidad de Villargordo; en Cádiz, sobre el Guadalete y en las proximidades de Jerez de la Frontera; y en Sevilla, donde existieron varias en distintos puntos del recorrido del Guadalquivir, como en Alcalá del Río, Villanueva del Camino y Bibarragel. Para el caso de Córdoba, la mayoría de estas barcas se encontraban en el Guadalquivir, muy conocidas fueron las situadas en el pago de Las Quemadas, entre Córdoba y Alcolea, la ubicada entre las aceñas de Lope García y las del Vado del Adalid, o la situada entre las villas de Pedro Abad y Adamuz ${ }^{90}$. Los derechos de pasaje eran cobrados en detrimento de la hacienda concejil, en el caso de Córdoba ya hemos comprobado el pago del pasaje de El Guijo o Moratilla. El precio del pasaje aumentaba en función de las circunstancias de la corriente, de este modo, cuando el caudal del río era mayor se incrementaba el importe del pago ante el peligro que ocasionaba. También el coste aumentaba dependiendo de los productos que se cargaban, aunque a veces existían exenciones de pago por la utilización de las barcas como sucedía en Almadén, Castilblanco, Castil de las Guardas, El Cerro y Carmona.

La mayor parte de las barcas debieron ser de un tamaño pequeño, dirigidas por una sola persona y provistas de remos para cruzar la corriente. Como se ha comentado anteriormente, muchas de ellas complementaban un puente o vado, un ejemplo de ello es el caso de Moratilla. Teniendo constancia de la existencia del pasaje para 1452, también se tiene noticia para esta misma fecha de las obras para la fabricación de un puente en el río Bembézar, cuyo inicio data de 1428 y hasta principios del siglo XVI no llegó a terminarse ${ }^{91}$. A pesar de que el puente estaba en construcción, el pasaje no dificultaba para nada la existencia de un futuro puente sino todo lo contrario, tendría una gran utilidad. De hecho, el camino existente

87. R. Córdoba de la Llave. "Navegación y transporte fluvial en la Península Ibérica a fines de la Edad Media", pp. 215-233.

88. Ibid.

89. Ibid.

90. Ibid.

91. J.L. del Pino García y E. Rojas. "Infraestructura viaria y pontonera medieval en torno al Bembézar”, Estudios de Historia y Arqueologia Medievales, XI (1996), pp. 365-415. 
entre Moratilla y Palma del Río atravesaba el río Bembézar sobre el puente homónimo dando muestra de que tanto éste como el pasaje se utilizaron sin problemas $^{92}$.

\subsubsection{Rentas procedentes de bienes raíces}

Este grupo de rentas solían surtir de destacados ingresos a la mayoría de los concejos de la corona de Castilla. En el caso de Córdoba, pueden ser clasificadas en función de su procedencia en tres tipos: las que estaban estrechamente relacionadas con el ámbito ganadero y agrícola (herbajes, montazgos, terrazgos, censos), las pertenecientes a las pesquerías y las obtenidas de inmuebles domésticos e instalaciones de carácter industrial (casas, tiendas, hornos, molinos, batanes, almonas, ollerías).

Centrándonos en el primer sector, el dedicado al mundo agropecuario, Córdoba recibía muy buenos ingresos del desembolso de las villas de su término. De esas rentas se han documentado en mayor medida los herbajes, terrazgos, dehesas y hazas, apareciendo en un segundo plano la asadura y el montazgo. Comenzando por el herbaje cordobés, entendido como el conjunto de hierbas que se criaban en pastos y dehesas, constituía un buen alimento para el ganado de manera que el concejo lo daba en arrendamiento anualmente a los ganaderos de su término. En el año 1452 esta renta de la hierba proporcionaba a la hacienda cordobesa 6.623 mrs.; las hierbas proceden de Santaella, la dehesa de La Parrilla y las situadas aguas abajo del Guadalquivir. No obstante, existieron muchos más herbajes en diversas dehesas; en 1480 se aconteció un conflicto por comer las hierbas cercanas al castillo de Benamejí, llegando incluso dos hombres a caballo, procedentes de la fortaleza de Benamexir, a tomar dos ovejas por la fuerza a Juan Jiménez del Barco, pastor y vecino de Castro del Río, y a Pedro de Andújar, su aparcero, las cuales se llevaron al citado castillo ${ }^{93}$.

92. R. Córdoba de la Llave. "Comunicaciones, transportes y albergues en el reino de Córdoba a fines de la Edad Media”, HID, 22 (1995), Sevilla, pp. 87-118.

93. 1480.01.24, AHPCO, PNCO, 13665P, 12, f. 3r. "Diego de Noguera, 24 de Córdoba y comendador de Benamexir (Benamejí), vecino de Baena, comparece junto con un hombre llamado Juan Jiménez del Barco, pastor, vecino de Castro del Río, para que éste último prestara declaración en cierto debate que el primero tenía por razón de su encomienda. El testigo dijo que él y Pedro de Andújar, su aparcero, yendo con cierto ganado ovejuno a buscar donde hallase herbaje para el dicho ganado, que pasando cerca del término de Guadamexir, que salieron a ellos de la fortaleza de Benamexir dos hombres a caballo, vasallos que fueron de él, donde estaba el ganado y les tomaron dos ovejas por fuerza y las llevaron al castillo de Benamexir, donde estaba Alfonso de Valderrama que había tomado el dicho castillo al alcaide que lo tenía por el citado comendador, y que el pastor y su compañero fueron al dicho castillo a demandar las ovejas, y Alfonso de Valderrama dijo que no se las daría hasta que se aviniesen con él para comer la hierba del término del dicho castillo con sus ganados, y ellos por no perder las ovejas, se avinieron con él y comieron la dicha hierba en su poder durante dos meses (...) y él y su compañero, estando con el ganado entre término de Benamexir y Antequera, les alancearon dos corderos muy buenos y se los llevaron a la fortaleza, y el pastor y su compañero fueron otra vez a la misma y Diego de la Barbera les dijo: amigos si queréis cobrar vuestros corderos volved al término, y que volvieron al término y estuvieron en él otro mes que se cumplió a dos días de este mes de enero, y entonces tenía la fortaleza Fernando Álvarez, y él y su compañero, salieron del término por las sinrazones que les hacían". 
En 1499 Luis García, vecino de Córdoba, tomó el herbaje a Antón López, vecino de Morente, de 200 cabezas de ovejas pagando por cada cabeza de terrazgo y herbaje 5 mrs. mensuales ${ }^{94}$. La hierba procedía de la dehesa del Canciller, situada en la campiña cordobesa. Un año después, Miguel Ruiz, vecino de Belmonte, debía pagar a Alfonso de la Tabla, carnicero y vecino de Córdoba, $1.600 \mathrm{mrs}$. del herbaje de dos meses y medio de 135 ovejas en la dehesa de la Alameda del Obispo ${ }^{95}$, y Alfonso y Lázaro López, vecinos de la villa de Cañete, tenían que pagar a Martín Alfonso de Montemayor, veinticuatro de Córdoba, $8.000 \mathrm{mrs}$. por la guarda y herbaje de 400 cabezas de ganado ovejuno en la dehesa del Aguilarejo durante 4 meses $^{96}$. En otros puntos de la Península también se documenta esta renta; en Chinchilla, los ganados que entrasen a gozar de las hierbas debían pagar 1 mrs. por cabeza; en Valencia, los ganados menudos pagaban 4 sueldos reales por cada 100 cabezas, $\mathrm{y}$ en caso de que no se pagase el derecho a herbajar el oficial podría exigirle el quinto $^{97}$. En Cuenca, el arrendamiento de las hierbas de las dehesas concejiles se realizaba en subasta pública ${ }^{98}$ y proporcionaba en 1450 entre 350 y 400 mrs. $^{99}$, una cuantía muy inferior si la comparamos con Córdoba para mediados del siglo XV. También se evidencia esta renta en Daroca en $1450^{100}$, en Tudela suponía una media de 500 libras a fines de la Edad Media, aumentado la renta del herbaje un 64,05 por 100 debido al encarecimiento de los pastos de la zona ${ }^{101}$. En Cartagena, Chinchilla, Almansa, Yecla, Júcar, entre otros muchos lugares, se aplicó el herbaje en toda su jurisdicción a mitad del siglo XIV ${ }^{102}$. Finalmente, en Sevilla también se

94. 1499.10.14, AHPCO, PNCO, 14138P, 4, f. 46v. "Luis García, vecino de Córdoba, toma a herbaje de Antón López, vecino de la villa de Morente, 200 cabezas de ganado ovejuno desde el día de la fecha al de año nuevo del año 1500, para traerlas en la dehesa que dicen del Chanciller en la campiña de Córdoba, que es de Diego López de Ayala, y que Antón López traiga con las dichas 200 cabezas de ganado su pastor, y dé para el mantenimiento del dicho pastor dos fanegas y media de trigo y una fanega y media de cebada para mantenimiento de los perros, y además otorgó darle por cada cabeza de terrazgo y herbaje $5 \mathrm{mrs}$. mensuales, y que le pague todo lo que monte el herbaje la semana antes de que saque el dicho ganado de las tierras".

95. 1500.12.14, AHPCO, PNCO, 14139P, 9, f. 14v.

96. 1500.11.17, AHPCO, PNCO, 14139P, 16, f. 35r.

97. J D. González Arce. La fiscalidad del señorío de Villena en la Baja Edad Media, Albacete, 2002, pp. 128-143.

98. Y. Guerrero Navarrete y J. M. Sánchez Benito. Cuenca en la Baja Edad Media: un sistema de poder urbano, Diputación Provincial de Cuenca, 1994, pp. 217-218. Para conocer más dehesas y herbajes en Murcia, ver el listado de la página 221.

99. J.A. Jara Fuente. "Identidad corporativa y constitución política urbana. Solidaridades económicas y poder en el marco de los procesos de afianzamiento de las rentas concejiles", en Y. Guerrero Navarro et alii. Fiscalidad, sociedad y poder en las ciudades castellanas en la Baja Edad Media, Universidad autónoma de Madrid, 2006, pp. 11-60.

100. M.I. Falcón Pérez. "Finanzas y fiscalidad de ciudades, villas y comunidades de aldeas aragonesas", Actas del V Congreso de Estudios Medievales. Finanzas y fiscalidad municipal, León, 1997, pp. 241-273.

101. J. Carrasco Pérez. "La hacienda municipal de Tudela a fines de la Edad Media (14801521)”, En la España Medieval, 7 (1985), pp. 1663-1700.

102. J.D. González Arce. "La fiscalidad agraria en el señorío de Villena en la Baja Edad Media", en R. Vallejo Pousada, A. Furió Diego (Coords.). Los tributos de la tierra: fiscalidad y agricultura en España: (siglos XII-XX), 2008, pp. 103-136. 
documenta el herbaje para 1479 con motivo de la deuda que mantenía Hernando Pinto, vecino de Gibraleón, con el concejo hispalense al reconocer el adeudo del herbaje de sus vacas, por 3.600 mrs., de la hierba del campo del Andévalo, renta que se negaba a abonar por el secuestro de las citadas vacas por parte del receptor de la Inquisición de la propia ciudad ${ }^{103}$. En Antequera se cobraba también el herbaje como una renta más dentro del aprovechamiento ganadero ${ }^{104}$.

La segunda renta que proporcionaba gran beneficio a Córdoba eran los arrendamientos de dehesas, que obviamente están estrechamente relacionadas con los herbajes. A veces en la documentación aparecen sin ningún tipo de información acerca de la utilidad que se les daba, pero en otras ocasiones conocemos su función y la renta aplicada, como por ejemplo para pastos (el ya citado herbaje) o de cara a la labor agrícola. Desde el siglo XIII muchas ciudades, dentro de sus bienes de propios, incluían este tipo de propiedad aplicándole una renta específica para obtener un beneficio económico. Cuenca tuvo desde 1386 el poder de adehesar propios en la Sierra, esto produjo la creación a partir de los años treinta del siglo XV de algunas dehesas como Fuente el Pinillo, Pared del Cuervo, Prado del Ciervo o Cañada el Mostajo, sometidas a nuevos amojonamientos para evitar usurpaciones indebidas $^{105}$. Murcia en 1277 contaba con la dehesa del Campo de Cartagena, que normalmente era arrendada para que los ganados trashumantes comieran el pasto, del mismo modo que está documentada en Jaén la dehesa del Abadía ${ }^{106}$. Por norma general, las arcas concejiles recibían un pago en metálico del arrendamiento efectuado, aunque a veces se permitía realizarlo en especie; así lo encontramos en la villa de Trujillo, donde el precio de la venta del pan dependía directamente de las dehesas de propios, ya que aquellas que eran de labor poseían la peculiaridad de pagar una parte en dinero y otra en grano ${ }^{107}$.

En la ciudad de Córdoba las dehesas también tuvieron un peso destacado en el total de ingresos de su hacienda. Dos de las principales eran las cobradas en Navas del Moro y Dos Hermanas ${ }^{108}$. En el documento del que nos servimos para este estudio se recogen más dehesas documentadas a lo largo de todo el siglo $\mathrm{XV}$, dehesas de La Parrilla, Los Ingenieros (Santaella), Villalobillos, Moratilla, Algallarín, Madroñiz, El Finojoso y Torre Catalina. La suma total de los ingresos proporcionados por todas ellas alcanzaba los $50.061 \mathrm{mrs}$, cifra importante dentro de los propios del concejo cordobés. A esto hay que añadir $10 \mathrm{mrs}$. de censo anual de ciertas tierras pertenecientes a la ciudad cordobesa que permitió, para los años 1452-1453, que el concejo de Torremilano adehesara con sus ganados y fueran ocupadas por el comendador Gonzalo Mejía. En Carmona también se ha documentado la existencia de dehesas pertenecientes a sus bienes de propios, como la

103. 1497.04.08, AGS, RGS, f. 255r-v.

104. A. Collantes de Terán Sánchez. "Ciudades y fiscalidad”, pp. 133-134.

105. Y. Guerrero Navarrete y J.M. Sánchez Benito. Cuenca en la Baja Edad Media: un sistema de poder urbano, pp. 216-217.

106. M.A. Ladero Quesada. "Las haciendas concejiles en la corona de Castilla", pp. 24-26.

107. Ma A. Sánchez Rubio. El concejo de Trujillo y su alfoz en el tránsito de la Edad Media a la Edad Moderna, Universidad de Extremadura, 1993, pp. 165-215.

108. M.A. Ladero Quesada. "Las haciendas concejiles en la corona de Castilla", pp. 24-26. 
dehesa del Concejo, cuyo nombre deja bien claro a quién pertenecía ${ }^{109}$. También Murcia y Sevilla disfrutaban de numerosas dehesas sometidas a arrendamiento con el fin de obtener sus respectivos ingresos, incluso aplicaban diversas penas sobre el uso de las mismas ${ }^{110}$.

En último lugar, debemos hablar de los terrazgos y las hazas, tasas que están bien documentadas en Córdoba. Tanto unos como otras, tierras vacantes y disponibles para la siembra, aparecen con frecuencia en la documentación bajomedieval. Para el período de 1452-1453 solamente aparecen las tierras vacadas situadas aquen del río de Guadalquivir syn Fornachuelos, cuyo ingreso ascendía a 1.895 mrs. Aunque no se indiquen datos concretos del rendimiento de las tierras de Córdoba, debían de obtenerse unas rentas sustanciosas, basta con ojear el trabajo de Ladero Quesada para observar el aumento de la producción y rentas cerealeras de Córdoba desde 1486 hasta $1502^{111}$. También las tierras de Carchena proporcionaron a la hacienda cordobesa suculentos ingresos desde 1487, hasta el punto de que el cabildo de 1495 envió a Diego Fernández Portichuelo a visitar estas tierras para comprobar qué barbechos quedaban ${ }^{112}$. Para el mismo año, Málaga comenzó a gozar de sus terrazgos ${ }^{113}$. Ya Alfonso X proporcionó tierras como bienes raíces a varias ciudades, proveyendo de 200 tahullas de tierra a Murcia y algunos terrenos a Sevilla como las Islas y marismas del Guadalquivir ${ }^{114}$.

Por su parte, el concejo de Carmona disponía de sus tierras concejiles, que arrendaba anualmente exigiendo como pago una cantidad determinada de cereal. Ni que decir tiene que dicha cuantía variaba en función de la producción que era obtenida cada año. Del mismo modo, esta villa poseía la denominada bellota del encinar, que era una renta aplicada a los encinales insertos dentro de los bienes de propios $^{115}$. Además de las tierras concejiles o terrazgos, los concejos castellanos contaban con una serie de hazas que solían dejarse a censo a los vecinos de cualquier villa, o en su caso, de la propia ciudad. Córdoba ingresó, en el periodo 1452-1453, solamente $40 \mathrm{mrs}$. del total de esta renta pues todas las localizadas en la ciudad estaban a censo, la denominada de los Barreros a Luis Mejía por $20 \mathrm{mrs}$., otra por $10 \mathrm{mrs}$. situada en el arroyo de la Cabrilla y una más en las ollerías de la puerta del Colodro que la llevaba el alguacil Pedro Tafur. Hasta finales del siglo XV se encuentran referencias acerca de censos sobre hazas; en 1492 Mencía de

109. M. González Jiménez. El concejo de Carmona a fines de la Edad Media (1464-1523), Sevilla, 1973, pp. 190-211.

110. $\mathrm{M}^{\mathrm{a}}$ del C. Veas Arteseros. Fiscalidad concejil en la Murcia de fines del medievo, Universidad de Murcia, 1991, pp. 78-183.

111. M.A. Ladero quesada. "Producción y renta cerealeras en el reino de Córdoba a finales del siglo XV”, Actas del I Congreso de Historia de Andalucía, vol. I, Córdoba, 1982, pp. 375-396.

112. 1495.01.02, AMCO, LAC, f. 1v.

113. M.A. Ladero Quesada. "Las haciendas concejiles en la corona de Castilla", p. 23.

114. A. Collantes de Terán Sánchez y D. Menjot. "La génesis de la fiscalidad municipal en Castilla: primeros enfoques", pp. 64-66.

115. M. González Jiménez. El concejo de Carmona a fines de la Edad Media (1464-1523), pp. 190-211. 
Gahete, tenía a censo un haza de tierra sin labrar de tres fanegas de trigo, pagaba por ella 400 mrs. y dos pares de gallinas al año ${ }^{116}$.

En último lugar, y como renta originaria de la tierra, podemos incluir la procedente del carbón de humo, muy demandado por la ciudad cordobesa, donde la tuvo de 1452 a 1453 Gómez Fernández de Santa Eufemia por 10.605 mrs. ${ }^{117}$. En este sentido, en Jerez o Carmona existía la montaracía, conjunto de ingresos generados por la elaboración de carbón en los montes concejiles, que durante el siglo XV acabó desapareciendo. Esta renta proporcionó a Carmona en 1484 unos 1.100 maravedís ${ }^{118}$. Si recopilamos todos los ingresos que gravaban el uso de la tierra de Córdoba, la cifra para mediados del siglo XV ascendía a $12.540 \mathrm{mrs}$.

Vistas las rentas procedentes del mundo agropecuario, es necesario estudiar el impuesto de las denominadas pesquerías. Ya hemos visto cómo los reinos de la España cristiana, incluso otros lugares de Europa como la Sicilia del siglo XII, heredaron varios aspectos de las haciendas musulmanas, y entre ellos se encontraban las rentas de las pesquerías, como las procedentes de las almadrabas de atunes ${ }^{119}$. Esta renta pesquera es bien conocida en muchas ciudades de la Península, por ejemplo en Toledo, donde aparecen muchos señoríos calatravos con este tipo de propiedades. En las siguientes líneas, hablaré someramente de algunos casos puntuales en la ciudad de Córdoba puesto que Pilar Hernández realizó un profundo estudio sobre esta temática ${ }^{120}$. Según Izquierdo Benito, se trataba de una renta que solía estar vinculada al uso de las presas o azudas que, por norma general, tuvieron una conexión directa con molinos harineros o el riego de las huertas; en aquellas se llevaba a cabo la labor pesquera realizando una rigurosa selección de pescados, anguilas, truchas, barbos, lampreas y peces comunes, aunque la variedad de pescado depende de la zona geográfica ${ }^{121}$. Cantera Montenegro explica que las pesquerías fluviales estaban instaladas en presas levantadas en los cauces de los ríos, contando con varias canales para facilitar la salida del agua ${ }^{122}$. Las pesqueras gallegas y portuguesas, localizadas en el Miño, estaban integradas por un sistema de muros de piedra que partían de las márgenes del río y que formaban obstáculos

116. 1492.05.30, AGS, RGS, f. 578r.

117. Para conocer más en profundidad la actividad carbonífera en Córdoba consultar: R. Córdoba de la Llave. La industria medieval de Córdoba, Córdoba, 1990, pp. 223-225 y J. López Rider. "La producción de carbón en el reino de Córdoba a fines de la Edad Media: un ejemplo de aprovechamiento del monte mediterráneo" (en prensa).

118. M. González Jiménez. El concejo de Carmona a fines de la Edad Media (1464-1523), pp. 213-214.

119. M.A., Ladero Quesada. "Estructuras y políticas fiscales en la baja Edad Media", Edad Media. Revista de Historia, 2 (1999), Universidad de Valladolid, pp. 113-150.

120. P. Hernández Iñigo. "La pesca fluvial y el consumo de pescado en Córdoba (1450-1525)", Anuario de Estudios Medievales, 27/2 (1997), pp. 1045-1116.

121. R. Izquierdo Benito. "El aprovechamiento del medio natural en el reino de Toledo durante los siglos bajomedievales", en J. Clemente Ramos (Ed.), El medio natural en la España Medieval: Actas del I congreso sobre Ecohistoria e Historia Medieval, Cáceres, 2001, p. 188.

122. S. Cantera Montenegro. "Los usos del agua en las cartujas de la corona de Castilla, en la transición del medievo al renacimiento", en J. Clemente Ramos (Ed.). El medio natural en la España Medieval: Actas del I congreso sobre Ecohistoria e Historia Medieval, p. 262. 
muy difíciles de superar por unos peces que, una vez obligados a desplazarse hacia los canales por donde penetraba el agua, podían ser fácilmente capturados ${ }^{123}$.

La actividad pesquera necesitaba del concurso de redes y nasas para permitir la captura de los peces que eran arrastrados corriente abajo por el curso fluvial. En Córdoba se documentan con frecuencia los utensilios empleados en las pesquerías, incluso los barcos; en Peñaflor el bachiller Alonso Téllez estaba encargado de investigar los daños ocasionados a la pesquería de Alonso Gil, situada en el río Guadalquivir, por parte del alcalde de Palma y de su señor, Luis Portocarrero, daños que el agraviado argumentaba explicando que:

(...) podía aver ocho días poco más o menos, que estando él en el rio de Guadalquivir teniendo echadas en el dicho rio sus redes e nasas en una su pesquerya, segund es uso e costumbre de pescadores, (...) un alcalde de la villa de Palma y Luys Puertocarrero con otras gentes, que nos estando él e ende, le tomaron las nasas o redes que asy tenía echadas en el dicho rio en la dicha su pesquerya (...) e que no es bastante aquello, mas dis que le echaron las dichas redes el ryo abaxo en tal manera que quando él dis que vino a restituyr sus nasas e pesquerya dis que lo falló todo perdido e que el barco quende tenía que se lo pasaron a la vanda e señorío del dicho Puertocarrero (... $)^{124}$.

El daño recibido superaba los 40.000 mrs. Un año después Diego Gutiérrez de los Ríos, veinticuatro de Córdoba, declaraba poseer una çerradura de pesquerya en el río Guadalquivir, para la que solicitaba defensa y amparo ${ }^{125}$. Conocemos su ubicación porque en 1485 se la arrendó a Martín Ruiz, vecino del Carpio, donde se especifica que se hallaba en las tierras del Castillo de la Alcolehuela, en la campiña de Córdoba, linderas con ribera y baldíos de la ciudad cordobesa, y permitía comer las hierbas y beber las aguas a los ganados hasta el día de San Miguel de septiembre siguiente. Ese lote de tierras donde se incluía la pesquería pagaba 3.000 mrs. de renta al concejo de Córdoba ${ }^{126}$. En 1484 Ruy Díaz, vecino de Córdoba, debía pagar 1.200 mrs. al alcaide Gonzalo del Castillo, mayordomo del corregidor Garcí Fernández Manrique, de la renta de su pesquería en el plazo de un año de azuda en azuda, desde la aceña de la rueda del Alcázar hasta la aceña de don Tello, con varias condiciones, que pudiera tomar la rama y la caña, tomar los peces que le demandare por $8 \mathrm{mrs}$. de descuento de la citada renta y no cortar álamos ni fresnos bajo pena de 1.000 mrs. ${ }^{127}$.

A veces se citan los tipos de peces que solían ser capturados con más frecuencia, y que por ello están insertos dentro del arrendamiento; en 1487 Francisco

123. M.L. Ríos Rodríguez. “Apropiación y organización social de un medio natural: pesca fluvial y pesqueras en la Galicia medieval”, en Mundos medievales, espacio, sociedades y poder: homenaje al profesor José Ángel García de Cortázar y Ruiz de Aguirre, Universidad de Cantabria, 2012, pp. 1827-1842.

124. 1490.02.22, AGS, RGS, f. 337r.

125. 1491.06.09, AGS, RGS, f. 193r.

126. 1485.11.18, AHPCO, PNCO, 14123P, 7, f. 209r.

127. 1483.03.07, AHPCO, PNCO, 13666P, f. 160v. 
García de Alzado, vecino de la villa de Lora, vendía a Pedro Fernández, trapero e hijo del jurado Martín Alfonso, vecino de Córdoba, todos los tipos de pescado (sábalos, anguilas, róbalos, albures, peces, bogas, sollos) que fuesen tomados en la pesquería de la azuda de Quintanilla en el río Guadalquivir, puestos al pie del canal de la misma; al precio cada docena de sábalos de 350 mrs., cada libra de anguilas, lobarros y albures $8 \mathrm{mrs}$., cada libra de peces y bogas $5 \mathrm{mrs}$. y por cada sollo, chico o grande, 450 mrs., desde la fecha de Pascua Florida siguiente ${ }^{128}$. Otras clases de peces, citados en las ordenanzas de 1435, son lenguados, corvinas, cazones, libias o mojarras ${ }^{129}$. También se hallaban pesquerías cerca del Puente de Alcolea, donde en 1486 el pelaire Francisco Fernández de Torrijos tenía a renta de la Catedral cordobesa tres medios batanes sobre el río Guadalquivir, con el canal y pesquería y la casa que tenía más arriba, por precio anual de $1.500 \mathrm{mrs}$, , aunque en este momento todo ello pasaba a ser propiedad de Juan de Ayala, señor de Cebolla ${ }^{130}$. Finalmente, podemos indicar pesquerías cercanas a otras villas de Córdoba, como las documentadas a escasa distancia de Montoro entre los años $1490 \mathrm{y}$ 1491, junto al batán del Acémila o Aceñuela y a la parada de aceñas de Arriba ${ }^{131}$. La única pesquería que el concejo de Córdoba mantenía en arrendamiento en los años 1452-1453 era la emplazada en el arroyo de la Cabrilla, que junto a un haza frontera importaba de censo $10 \mathrm{mrs}$. anuales.

Dentro de las rentas concejiles debemos incluir también las procedentes de bienes inmuebles. Desde la época de la conquista y con el paso del tiempo, sobre todo en el siglo $\mathrm{XV}$, los concejos urbanos comenzaron a recibir casas, tiendas, hornos, carnicerías, ollerías, herrerías, batanes, que les proporcionaban el importe de las rentas y tributos aplicados sobre ellos. Lo normal es que fuesen arrendados a través de censos a vecinos de la ciudad o de villas terminiegas, como se documenta en Córdoba y Sevilla ${ }^{132}$. La mayoría de estos bienes eran de carácter urbano y no se hallaban adscritos al uso común de los vecinos como ocurre con otros patrimonios. Otro rasgo que identifica a estas instalaciones es que, en su mayor parte, se

128. 1487.08.16, AHPCO, PNCO, 13666P, f. 775v.

129. M. González Jiménez. "Ordenanzas del concejo de Córdoba (1435)”, HID, 2 (1975), Sevilla, pp. 191-315.

130. 1486.01.30, AHPCO, PNCO, 13666P, f. 377v.

131. 1491.07.29, AHPCO, PNCO, 14129P, 6, f. 18r. "Juan de Angulo, comendador de las casas de Córdoba de la Orden de Calatrava, arrienda a Martín Fernández del Pozo, vecino de Montoro, un batán en el río Guadalquivir en la parada de Pajares, cerca de la villa de Montoro, que se dice el batán del Acémila o del Aceñuela, moliente y corriente con sus pertrechos y aparejos, y con la pesquería desde el dicho batán hasta el vado, desde san Juan de junio por todos los días de su vida y renta anual de 5.000 mrs. y 20 pares de gallinas". 1490.07.21, AHPCO, PNCO, 13668P, f. 870v. "Catalina Méndez de Sotomayor, viuda de Suero Méndez de Sotomayor, 24 que fue de Córdoba, y Gonzalo Méndez de Sotomayor, su hijo, vecinos de Córdoba, arriendan a Bartolomé González de la Fuentecaliente, molinero, y a su mujer Marina Fernández, vecinos de Montoro, una piedra de aceña de pan moler que ellos poseen en la parada de aceñas que dicen de Arriba, en el río Guadalquivir cerca de la villa de Montoro, la cual piedra se dice la Pajaza, lindera con piedra de aceña de Pedro Méndez de Sotomayor, piedra de aceña de Diego de Aguayo y piedra de aceña de Rodrigo y Lope de Rabé, por tiempo de 4 años y renta anual de 27 cahices de trigo. Y se la arrienda con la parte de pesquería y canal que a la dicha piedra de aceña pertenece".

132. A. Collantes de Terán Sánchez. "Ciudades y fiscalidad”, p. 135. 
hallaban vinculadas con los sectores mercantiles o artesanos, llegándose incluso a incluir las calderas de teñir paños o las almonas ${ }^{133}$. En ocasiones algunas de estas propiedades urbanas procedían de época musulmana y acabaron en manos del rey que las mantenía como propiedad para obtener una fuente de ingresos fija, o a veces para cederlas a instituciones y/o particulares; las alhóndigas de Córdoba fueron prestadas a particulares por el propio Fernando III, del mismo modo la alcaicería y la almotaclacía fueron cedidas por Enrique III a miembros de la aristocracia urbana ${ }^{134}$; Mercedes Borrero ha documentado numerosos censos aplicados sobre inmuebles en las haciendas de los concejos rurales de Sevilla ${ }^{135}$.

Centrándonos en Córdoba, los ingresos que procedían del patrimonio inmueble son bastante significativos, pues su cuantía ascendía a $5.855 \mathrm{mrs}$. en 14521453. Teniendo en cuenta la complejidad de la enorme diversidad de propiedades que pertenecían a los concejos castellanos, se ha realizado una pequeña clasificación para el caso de Córdoba, desglosando la tipología y la cifra que aportaba para la hacienda: Hornos, 585 mrs.; Casas-Tinte de la Aduana, varias casas de La Corredera y Casas de la Red, 5.250 mrs.; Molino de Gahete, 10 mrs.; Casilla de la Fuente de San Pablo, 10 mrs.

Es evidente que las viviendas soportan el grueso de los ingresos de la hacienda cordobesa en cuanto a bienes inmuebles se refiere. Si analizamos los hornos, todos ellos proceden de las villas del concejo cordobés, como los ubicados en Peñaflor, Fuente Ovejuna, Bujalance (donde se documentan dos, ya que existía un solar que era utilizado como horno), Santaella y La Rambla. De todos ellos, el que mayor beneficio dejaba era el de Fuente Ovejuna, $400 \mathrm{mrs}$. anuales. Otros ejemplos de explotación de hornos concejiles los encontramos en Ávila, Zamora ${ }^{136}$, Sevilla o Murcia ${ }^{137}$. En cuanto a las casas, existen varios tipos según el uso al que estuvieran dedicadas. Las Casas-Tinte localizadas en la Aduana indican claramente su finalidad; fueron repartidas entre dos tintoreros, Pedro Díaz de Jerez y Jaime Martín, que pagaban 13 doblas castellanas $(1.950 \mathrm{mrs}$.) de arrendamiento anual. Las denominadas casas de La Corredera contribuían con 18 doblas castellanas (2.700 mrs.) y las tenía en arrendamiento Juan Rodríguez, odrero. En Carmona el concejo también poseía una serie de casas que arrendaba anualmente, o a perpetuidad a través de un censo, y lo mismo ocurría con algunas tiendas de su entramado urbano ${ }^{138}$.

Respecto a las Casas de la Red aportaban al fisco cordobés 4 doblas (600 mrs.). Para finales del siglo XIV y principios del XV, la renta del diezmo del pescado fresco se recogía en alguna de estas casas en la collación de Santa María, junto

133. M.A. Ladero Quesada. El siglo XV en Castilla, pp. 23-25.

134. M.C. Quintanilla Raso. "Notas sobre el comercio urbano en Córdoba durante la Baja Edad Media", Actas del I Congreso de Historia de Andalucía. Andalucía Medieval, vol. I, Córdoba, 1982, pp. 413-422.

135. M. Borrero Fernández. "Las haciendas de los concejos rurales sevillanos", Actas del II Coloquio de Historia Medieval Andaluza. Hacienda y comercio, Sevilla, 1981, pp. 67-79.

136. M.A. Ladero Quesada. "Las haciendas concejiles en la corona de Castilla", p. 31.

137. $\mathrm{M}^{\mathrm{a}} \mathrm{del} \mathrm{C}$. Veas Arteseros. Fiscalidad concejil en la Murcia de fines del medievo, pp. 78-183.

138. M. González Jiménez. El concejo de Carmona a fines de la Edad Media (1464-1523), pp. 211-212. 
con la alcabala antigua ${ }^{139}$. Su uso está estrechamente relacionado con la actividad pesquera puesto que tenemos constancia de la existencia de la renta de la Red en otros puntos de la geografía peninsular, por ejemplo en Zamora, donde dicha renta de carácter ordinario era muy variable en función del tipo de pescado comercializado $^{140}$. En Guadalajara, a finales del siglo XV, se tienen datos de la existencia de la casa de la pescadería o red, que era el lugar principal de la venta del pescado ${ }^{141}$. Como bien explica López Villalba, la red del pescado era el sitio más concurrido para la venta al público de los diferentes productos de índole fluvial y marítima, ya que anteriormente - tanto las ciudades como las villas no gozaban de un lugar habilitado para tal fin-se vendían en tablas a través de comerciantes ambulantes, careciendo totalmente de higiene ${ }^{142}$. La casa de la Red existía también en Madrid en 1502 y en algunos de los concejos rurales sevillanos a fines de la Edad Media ${ }^{143}$.

En último lugar, tanto el molino de Gahete ${ }^{144}$ como la casilla de la Fuente de San Pablo, contribuían mínimamente en las arcas cordobesas. Solamente proporcionaban $20 \mathrm{mrs}$. en 1452 (10 mrs. cada uno), estando el primero arrendado a censo anual a Martín Alonso, vecino de Gahete, y la casilla a Alonso Méndez. Otros inmuebles como ollerías, alfares, grúas, almonas, salinas o carnicerías, podían también pertenecer a los concejos $\mathrm{y}$, por tanto, estar sometidos a unas rentas que alimentaban anualmente a la hacienda concejil; en Tudela, el impuesto de la carne era el tributo más importante pagándose una blanca por cada libra de carne vendida en las tiendas ${ }^{145}$. En Sevilla la elaboración del jabón y su venta era un monopolio inserto en la renta de los almojarifazgos de los reyes cristianos de manera que, en alguna ocasión, fue cedida al concejo, aunque por lo general se vinculó a las familias más nobles de la ciudad ${ }^{146}$. Este hecho también es aplicable a otras ciudades, pues en Córdoba las jabonerías estaban en manos de particulares, aunque no sabemos qué monarca otorgó ese disfrute ni tampoco en qué familias se dejó ese beneficio. Habría que destacar la concesión por parte de Enrique III a Leonor López, hija del maestre de Calatrava Martín López de Córdoba, de las rentas de

139. J.M. Escobar Camacho. "Economía urbana de Córdoba durante la época de los RR.CC.", p. 203.

140. Y. Guerrero Navarrete. "Impuestos y contribuyentes en los concejos de la Meseta Norte", Actas del V Congreso de Estudios Medievales. Finanzas y fiscalidad municipal, León, 1997, p. 394.

141. J.M. López Villalba. "Política local y abastecimiento urbano: el pescado de Guadalajara en la Baja Edad Media”, Studia Histórica. Historia Medieval, 25 (2007), pp. 221-234.

142. Ibid., p. 231.

143. M. Borrero Fernández. "Las haciendas de los concejos rurales sevillanos", pp. 67-79.

144. J. López Rider. Estudio sobre construcciones hidráulicas e industriales de Santaella (Córdoba), Diputación de Córdoba, Córdoba, 2013, pp. 134-135. Existían numerosos molinos concejiles ubicados en las diversas villas del alfoz cordobés, en Santaella por ejemplo, para finales del siglo XV se pedía licencia al propio concejo de Córdoba para la fabricación del molino de don Martín, en la isla del Membrillar, junto al vado Bermejo.

145. J. Carrasco Pérez. "Sobre la hacienda municipal de Tudela a fines de la Edad Media (14801521)", en Historia de la Hacienda española: (épocas antigua y medieval): Homenaje a Luis García de Valdeavellano, Ministerio de Hacienda, Instituto de Estudios Fiscales, 1982, pp. 127-169.

146. M.A. Ladero Quesada. "Las haciendas concejiles en la corona de Castilla", p. 33. 
una tienda de jabón en la ciudad cordobesa ${ }^{147}$. De las pocas obligaciones que se imponía a los arrendadores era que procurasen un mínimo de abastecimiento a la ciudad como bien se recoge en las ordenanzas de 1493:

Otrosy, por quanto acaesce que algunos vezinos han mengua de xabón en esta cibdad, mandamos que los señores del dicho xabón e sus arrendadores den cumplimiento e batescan de xabón, e cada que fallesciere, quel conceio remedie como entendiere que cumple ${ }^{148}$.

Incluso más adelante se recoge el nombre de una jabonería vinculada, casualmente, a la familia Sosa:

En veynte e syete días del mes de março, año del nascimiento del nuestro Saluador Ihesus Xpisto de mill e quatrocientos e noventa e tres años, que asentaron con Gonçalo de Cárcamo e Juan de Sosa, por sy e en nombre de sus consortes cuya es el almona de los herederos de Juan Alonso de Sosa, que Dios aya, que de aquí adelante para syempre jamás (...) e los dichos señoríos se obligaron a dar abasto de xabón en la dicha almona, segund que está asentado en los libros del cabildo e ante escriuanos públicos (...) $)^{149}$.

Junto a la promulgación de estas normas, el concejo también estipulaba los precios de venta del jabón en función del valor que tuvieran los ingredientes usados para su elaboración. En un pleito de 1477, acerca del cumplimiento de la renta del jabón de la ciudad de Córdoba, aparecen varios nombres de los que gozaban de las dichas jabonerías por merced real, Gonzalo Carrillo, Egas Venegas, Pedro Tafur, Alfonso de Aguayo, todos ellos eran veinticuatros y regidores de la ciudad de Córdoba, y Juan de Lisón y Luis de Valladares. Estos propietarios se quejaban del incumplimiento de lo reflejado en las cartas de merced real que poseían sobre las rentas del jabón de la ciudad, culpando a Juan Alonso de Sosa y su mujer, porque con el quebrantamiento de los privilegios del resto de beneficiarios estaban aprovechándose de la renta del jabón. El veredicto final consistió en el cumplimiento de las cartas de merced real y se les devolvieron a los agraviados el derecho y privilegio de todas aquellas almonas que les pertenecían ${ }^{150}$.

\subsubsection{Otras rentas concejiles}

Continuando con la relación de cuentas del concejo de Córdoba para mediados del siglo XV, solamente quedarían por citar cinco impuestos que proporcionaron un total de $80.242 \mathrm{mrs}$., sin duda una suma muy notable para la economía cordobesa.

147. E. Mitre Fernández. "Córdoba y su campiña. Una comarca fronteriza al comienzo del siglo XV", Cuadernos de Estudios Medievales, I (1973), p. 17.

148. AMCO, OM, Libro $1^{\circ}$, f. 203 r-v.

149. Ibid.

150. 1477.10.03, AGS, RGS, f. 56r. 


\subsubsection{Multas, penas o caloñas}

Todas las haciendas municipales suelen coincidir en la tipología de algunas de sus rentas, y este es sin duda el caso de las denominadas multas, penas y calumnias o caloñas. Todos los núcleos imponían ciertas sanciones y castigos sobre aquellos vecinos que no cumpliesen las normas contenidas en las Ordenanzas municipales, aunque no siempre su importe llegara directamente a las arcas concejiles puesto que era habitual tenerlo compartido ${ }^{151}$. A menudo el importe de la multa se repartía entre el denunciante y el propio concejo; en otras ocasiones se destinaba a retribuir total o parcialmente a los oficiales responsables de su imposición ${ }^{152}$. Incluso en otros casos, la cuantía ingresada era utilizada para algún fin concreto, reparo de muros, pago de quitaciones o cualquier gasto extraordinario. Las penas o castigos eran aplicados a diversos aspectos; ya en el último tercio del siglo XIII la Corona cedió a los concejos la imposición de las penas sobre los juegos ilegales celebrados en casas de juegos o tafurerías. Enrique III concedió al concejo cordobés las rentas de las tahurerías y en 1421 Juan II se las dejó a Álvaro de Luna y al almirante Alfonso Enríquez, a cambio de que los jurados obtuvieran 20.000 mrs. anuales con cargo a la hacienda regia ${ }^{153}$. También existía la renta y las penas del juego en Murcia, Sevilla, Oviedo, Baeza, Úbeda, Jaén, Valladolid, Sevilla o Jerez.

En la Corona de Aragón son igualmente frecuentes los ingresos por sanciones y multas sobre actividades lúdicas ${ }^{154}$. En Zaragoza la renta se denominaba calonias de los juegos ${ }^{155}$. Igualmente eran penados el consumo, el uso de dehesas y veredas concejiles donde los jueces de términos estaban obligados a intervenir continuamente, la fabricación de ciertos productos de la ciudad, la mala utilización de las aguas comunes, no respetar la higiene del entramado urbano, el comportamiento de carniceros o pescaderos, la importación ilegal de productos como el aceite o el vino, entre muchas otras. Ante tal diversidad, es muy difícil establecer una clasificación fidedigna de los tipos de castigos y penas, sin embargo, sí podemos mencionar algunos ejemplos de aquellas multas mejor documentadas. En Córdoba las sanciones más frecuentes y cuantiosas a mediados del siglo XV eran las de los corredores, que fueron arrendadas en $11.000 \mathrm{mrs}$; y las penas impuestas a quienes transgredían las Ordenanzas municipales, que alcanzaba los $46.000 \mathrm{mrs}$. En los años 1452 y 1453 se ingresaron 57.000 mrs. solamente de multas para las arcas cordobesas. En Sevilla, las penas incurridas por los arrendatarios de la sal

151. A. Collantes de Terán Sánchez. "Ciudades y fiscalidad”, pp. 129-149.

152. M.A. Ladero Quesada. "Las haciendas concejiles en la corona de Castilla”, pp. 8-71.

153. F. Mazo Romero. "Tensiones sociales en el municipio cordobés en la primera mitad del siglo XV", Actas del I Congreso de Historia de Andalucía. Andalucía Medieval, vol. II, Córdoba, 1982, pp. 85-112.

154. E. Sarasa Sánchez. “Concejos y ciudades medievales en el reino de Aragón. Hacia una tipología socioeconómica de los municipios aragoneses en la Edad Media: De la foralidad a la municipalidad", Actas del II Congreso de Estudios Medievales. Concejos y ciudades en la Edad Media hispánica, Móstoles, 1990, pp. 73-122.

155. B. Palacios Martín y M.I. Falcón Pérez. "Las haciendas municipales de Zaragoza, a mediados del siglo XV (1440-1472)", en Historia de la Hacienda española: (épocas antigua y medieval): Homenaje a Luis García de Valdeavellano, Ministerio de Hacienda, Instituto de Estudios Fiscales, 1982, pp. 539-606. 
iban destinadas al concejo, sin embargo, si atentaban contra los propios arrendatarios eran para éstos ${ }^{156}$. Muy frecuentes y numerosas son las infracciones sobre cortes y quemas de montes, como en Trujillo ${ }^{157}$, la propia Córdoba, Jaén, Huelva, Toledo o Sevilla.

\subsubsection{Impuestos sobre comunidades étnico-religiosas}

Otra de las rentas que comúnmente se documenta en la mayoría de las haciendas concejiles es la aplicada sobre poblaciones judías y mudéjares sometidas al pago de unos gravámenes directos específicos que les otorgaba cierta especialidad dentro de los grupos sociales que constituían el reino ${ }^{158}$. Los impuestos mudéjares son denominados de diferente modo según cada comarca, alfarda en Valencia, pecha o peyta en Aragón, questia en Cataluña,farda en el reino de Granada, pecho de los moros en Andalucía; todos ellos se designan en la documentación mudéjar con el término común de Al-gizya $^{159}$. El más reconocible en las fuentes documentales cristianas es el llamado cabeza del pecho o simplemente pecho, que consistía en el pago de una cuantía anual que cada mudéjar estaba en la obligación de realizar para reconocer al monarca como su señor y recibir la protección de éste ${ }^{160}$. Ya en el reinado de Sancho IV existen referencias de esta renta en las relaciones de cuentas; no obstante, será Enrique III quien fije por última vez el gasto para cada morería ${ }^{161}$. Normalmente el pecho de los moros era pagado en metálico y solo era ineludible para los moros adultos o la aljama en su conjunto ${ }^{162}$. La recaudación en el interior de las aljamas se realizaba por cadíes o consejo de ancianos, siguiendo las normas islámicas que especificaban los tratados de jurisprudencia (al-Tafri $)^{163}$.

La cabeza del pecho de los moros en Sevilla ascendía a 5.500 mrs. en 1294, contribuyendo con 1.000 mrs. al año sobre el almojarifazgo real para reparo de los caños de agua ${ }^{164}$. En Tudela, además de las penas que se imponían sobre aquellos cristianos que compraban carne en las aljamas de judíos y moros, estos últimos pagaban el doble que los hebreos, aunque dependía mucho de las normas imperantes en el interior de cada aljama ${ }^{165}$. En el caso concreto de Córdoba, desde 1254 y

156. J.D. González Arce. "Las rentas del almojarifazgo de Sevilla", Studia Histórica, Historia Medieval, 15 (1997), pp. 209-254.

157. MaA. Sánchez Rubio. El concejo de Trujillo y su alfoz en el tránsito de la Edad Media a la Edad Moderna, pp. 165-215.

158. M.A. Ladero Quesada. La Hacienda real de Castilla en el siglo XV, pp. 218-219.

159. S. Abboud Haggar. "Leyes musulmanas y fiscalidad mudéjar", pp. 176-177.

160. Ibid.

161. J.D. González Arce. La fiscalidad del señorio de Villena en la Baja Edad Media, p. 330.

162. M. González Jiménez. "Fiscalidad regia y señorial entre los mudéjares andaluces (siglos XIII-XV)", en Actas del V Simposio Internacional de Mudejarismo, Teruel, 1991, pp. 221-240.

163. S. Abboud Haggar. "Leyes musulmanas y fiscalidad mudéjar", pp. 176-177.

164. M.A. Ladero Quesada. "Las transformaciones de la fiscalidad regia castellano-leonesa en la segunda mitad del siglo XIII (1252-1312)", en Historia de la Hacienda española: (épocas antigua y medieval): Homenaje a Luis García de Valdeavellano, Ministerio de Hacienda, Instituto de Estudios Fiscales, 1982, pp. 323-406.

165. J. Carrasco Pérez. "Sobre la hacienda municipal de Tudela a fines de la Edad Media (14801521)", pp. 127-169. 
a través de Alfonso X la ciudad obtuvo 500 mrs. por San Miguel gracias el pecho de los moros para labrar la muralla ${ }^{166}$. A finales de 1263 se ordenó que se asignara otra renta de $30 \mathrm{mrs}$. sobre la aljama de los moros para la conservación de unas conducciones de agua. En 1386, Juan I le cedió al concejo cordobés la renta de la aljama de los $\operatorname{moros}^{167}$. Llegados al siglo XV, la hacienda de Córdoba ingresaba $7.000 \mathrm{mrs}$. anuales de dicha aljama desglosados en dos rentas, $1.000 \mathrm{mrs}$. por el derecho de la carne de los moros de la propia aljama y $6.000 \mathrm{mrs}$. por la cabeza del pecho de los mismos. En 1477 Ruy Díaz de Vargas y Alfonso Ruiz del Castillo, veinticuatro de Córdoba, entablaron un pleito sobre las rentas de la exea, meaja, correduría y algarfa de lo morisco en esta ciudad ${ }^{168}$. Los estudios sobre mudéjares y fiscalidad en el reino de Granada evidencian que la contribución de esta renta era inferior que las analizadas hasta el momento, pero aun así significativa ${ }^{169}$.

\subsubsection{Aguadores o azacates}

La tercera renta aportaba menos ingresos que las anteriores, la denominada de los azacanes o aguadores. En muchos concejos apenas se ha documentado por la escasa importancia que tenía su contribución económica, aunque su peso en el total de los ingresos dependía directamente de las realidades económicas de cada cabildo. En este sentido, el acarreo y distribución del agua sometida a renta aparece en ciudades como Astorga, Palencia, Segovia, Madrid, Cáceres, Jerez o Córdoba $^{170}$.

Para el concejo de Carmona se conoce bastante bien el oficio de los aguadores, que era regularmente ejercido por los esclavos. Por norma general recibían 1 $\mathrm{mr}$. al día todos aquellos azacanes que obtuvieran más de 2 o 3 cargas diarias de agua de una fuente concejil. Por otra parte, existía cierta tolerancia y permisividad hacia aquellos otros aguadores que tenían menos recursos y eran más humildes, permitiéndoles que si vendían con su cántaro de agua a cuestas, estuvieran exentos del pago de este impuesto. Lo mismo era aplicado al agua transportada y llevada a casa del amo, tampoco debían pagar nada ${ }^{171}$. Para valorar lo que aportaba esta

166. M.A. Ladero Quesada. El siglo XV en Castilla, pp. 19-20; y M.A. Ladero Quesada, "Las transformaciones de la fiscalidad regia castellano-leonesa en la segunda mitad del siglo XIII (12521312)", pp. 323-406.

167. E. Mitre Fernández. "Córdoba y su campiña. Una comarca fronteriza al comienzo del siglo XV", p. 19.

168. 1477.10.19, AGS, RGS, f. 117r-v.

169. A. Galán Sánchez. "Poder y fiscalidad en el reino de Granada tras su conquista: algunas reflexiones", Studia Histórica. Historia Medieval, 30 (2012), pp. 67-98; o del mismo autor, "Hacienda y fiscalidad en el reino de Granada: algunas razones para su estudio", Chronica nova: Revista de historia moderna de la Universidad de Granada, 31 (2005), pp. 11-22; con R.G. Peinado Santaella. "De la madina musulmana al concejo mudéjar: fiscalidad regia y fiscalidad concejil en la ciudad de Granada tras la conquista castellana", en M. Sánchez Martínez y D. Menjot (Coords.). Fiscalidad de Estado y fiscalidad municipal en los reinos hispánicos medievales, Casa Velázquez, 2006, pp. 197-238.

170. M.A. Ladero Quesada. "Las haciendas concejiles en la corona de Castilla", pp. 8-71.

171. M. González Jiménez. El concejo de Carmona a fines de la Edad Media (1464-1523), p. 224. 
renta, en los años 1452-1453 el concejo cordobés solamente obtuvo $1.700 \mathrm{mrs}$. anuales de beneficio.

\subsubsection{La meaja del medir de los paños}

El impuesto o renta de la meaja del medir de los paños tampoco fue muy boyante para Córdoba, aunque el sector textil era otro filón aprovechado por aquellas ciudades que necesitaban a toda costa obtener ciertos ingresos para sobrevivir. El origen de esta tasa es difícil de conocer, quizás como indica Manuel González Jiménez proceda del pago de la meaja, medio maravedí por paño. Conforme avanzó el tiempo aumentó su valor manteniendo su denominación original ${ }^{172}$. Lo que sí podemos afirmar es que se trataba de un gravamen concejil que era aplicado a la venta de todas las piezas textiles que entraban en la ciudad ${ }^{173}$. Tanto en Carmona como en Córdoba se aplicaba sobre las telas traídas por comerciantes forasteros para su comercialización ${ }^{174}$, lo cual era debido a la gran demanda ejercida por los grupos sociales que disponían de mayores recursos económicos y cuyos gustos obligaban a las ciudades a importar paños de una calidad superior. No obstante, las necesidades del mercado local eran abastecidas por las telas que fabricaban los propios tejedores del entorno. Las piezas textiles que procedían de fuera estaban obligadas a pagar los derechos de entrada, pero también el impuesto concejil de la meaja, que correspondía a la tercera parte de la alcabala ${ }^{175}$.

Son conocidos los paños de Zamora, Logroño, Ciudad Rodrigo, Talavera, Carmona, Córdoba, Sevilla y Cuenca ${ }^{176}$. Los más costosos y demandados por los grupos más pudientes eran sergas, sayales, fustanes y frisas. El concejo de Carmona en 1466 obtuvo 900 mrs. de beneficio, aunque su valor medio alcanzaba una cifra muy superior llegando a los $8.000 \mathrm{mrs} .{ }^{177}$. En comparativa con el concejo de Córdoba, los ingresos de esta fueron muy inferiores a los de la capital hispalense, montando solo 100 mrs. para el año de 1452. A pesar de ello, en 1490 se evidencia que el concejo cordobés manejaba cantidades mucho más elevadas, pues el arrendamiento de la meaja del medir de los paños se remató en pública almoneda por $10.000 \mathrm{mrs}$. en un particular llamado Juan de $\mathrm{Cea}^{178}$. Asimismo aparece en la documentación de la época, la tasa aplicada a los sayales y linos cordobeses ${ }^{179}$. Para llevar a cabo una óptima recaudación, el trapero o comerciante de piezas textiles comunicaba en un plazo de tres días al arrendador encargado de la meaja, la cantidad y tipología de paño que vendió, a quién se la entregó y por qué pre-

172. M. González Jiménez. "Ordenanzas del concejo de Córdoba (1435)”, pp. 191-315.

173. J.M. Sánchez Benito. "Las haciendas de los concejos en la Submeseta sur", Actas del V Congreso de Estudios Medievales. Finanzas y fiscalidad municipal, León, 1997, pp. 397-428.

174. M. González Jiménez. El concejo de Carmona a fines de la Edad Media (1464-1523), pp. 224-225.

175. Ibid.

176. M.A. Ladero Quesada. "Las haciendas concejiles en la corona de Castilla", pp. 8-71.

177. M. González Jiménez. El concejo de Carmona a fines de la Edad Media (1464-1523), pp. 224-225.

178. 1490.12.16, AGS, RGS, f. 238r-v.

179. A. Collantes de Terán Sánchez. "Ciudades y fiscalidad”, pp. 129-149. 
cio $^{180}$. Esta regulación no es nada extraña puesto que en Córdoba la industria textil gozaba de gran peso y las oportunidades que brindaba respecto a las actividades de los productores de menor entidad eran muy valoradas. Las collaciones de San Nicolás de la Ajerquía, San Andrés y San Pedro, concentraban la producción de paños de mayor calidad ${ }^{181}$.

\subsubsection{Renta de las velas}

La última de las rentas concejiles encontradas en el documento que se inserta en el presente trabajo, son las denominadas velas. Hasta el momento, poco o nada se sabe de este impuesto, pues siempre se ha relacionado con las guardas que hacen los vecinos de la tierra, con escuchas, rondas y vigilancia de las puertas de la ciudad o cualquier otro lugar ${ }^{182}$. Sin embargo, las velas documentadas en Córdoba tienen otra finalidad totalmente distinta a la que le otorgó en su día John Edwards, puesto que no se trata de guardas o vigilancias sino de la prohibición por la utilización de velas entendidas como una herramienta para la iluminación. El primer indicio que descarta la vertiente militar es que se contabiliza como un ingreso y no como un gasto, es decir, no tendría mucho sentido que los vecinos de la ciudad pagasen al concejo de Córdoba por hacer vigilancia; la segunda prueba la encontramos en la noticia más temprana hallada para esta renta, localizada en el reinado de Enrique III, concretamente en 1401, donde se pide que la ciudad destine el dinero obtenido de las velas para sufragar el gasto de los sueldos de porteros, velas y rodas ${ }^{183}$. Aquí se distingue bien las dos clases de velas, es decir, el dinero recaudado a través de las velas de iluminación, serían destinadas al pago de las velas de vigilancia. En 1452 la hacienda de Córdoba recibía 14.442 mrs. procedentes de las velas del cuerpo de la ciudad, las velas del río arriba y abajo del Guadalquivir, las de Fuente Ovejuna y las de Pedroche. El concejo de Córdoba incluso tenía un arrendador de las velas de la ciudad, que en 1479 era Rodrigo de Rojas y que percibía 400 mrs. al año ${ }^{184}$.

En diciembre de 1497 volvemos a encontrar una mención a este impuesto concejil, pues aparece Alonso Enríquez, corregidor de Córdoba, guardando una carta anterior que fue entregada a petición de los caballeros de premia y la comunidad de la dicha ciudad. En ella se mandaba recabar toda la información que fuera posible sobre las velas que se llevaban en la población y su tierra, dando lugar al conocimiento de lo que habían rentado en los últimos cinco años ${ }^{185}$. Asimismo,

180. M. González Jiménez. “Ordenanzas del concejo de Córdoba (1435)”, pp. 191-315.

181. J. Edwards. "Las peculiaridades económicas de la Andalucía Bajomedieval: el caso de Córdoba", Actas del II Coloquio de Historia Medieval Andaluza. Hacienda y comercio, Sevilla, 1981, pp. 125-131.

182. J. Rodríguez Molina. “Algunos datos sobre la actividad comercial y fiscal en Jaén y Baeza a fines del siglo XV”, pp. 159-176.

183. 1401.11.15, AMCO, C-1161, doc. 2.1, f. 1r. Aquí se distingue bien las dos clases de velas, es decir, el dinero recaudado a través de las velas de iluminación, serían destinadas al pago de las velas de vigilancia.

184. 1479.09.28, AMCO, LAC, f. 73r.

185. 1497.12.15, AGS, RGS, f. 89r. 
para enero del mismo año, con motivo de la petición hecha por la comunidad de Córdoba al corregidor sobre que se pudiera vender la harina de la alhóndiga a peso y no por medida, igual que ocurría en Sevilla, con la finalidad de que pudieran beneficiarse los pobres que deseaban hacer la compra en pequeñas cantidades, se incluía otra reclamación dirigida contra la recaudación de las velas que se solía coger a la gente pobre, la cual estaba obligada a pagar $2 \mathrm{mrs}$., y en caso de que no los pagasen, eran apresados y obligados a pagar otros 2 mrs. adicionales por prenda. Es decir, en ocasiones llegaban a pagar $4 \mathrm{mrs}$. En el documento se plasma lo siguiente:

Otrosy, hizo relación diciendo que en esta dicha çibdad e en su tierra, se cogieron çiertas velas de la gente común e pobre, e que los que tyene de las mandar recaudar las manda pagar a dos maravedís cada vela, e que sy los que las fan de pagar no pagan, al primer requerimiento que les fasen sean prendadas por otros dos maravedis, e que lo que peor es que se pierde las prendas, como son de personas pobres e asy mendicantes (...) $)^{186}$.

Del mismo modo, en 1500 se notificaron a los Reyes Católicos nuevas quejas por el coste de las velas. Juan Pérez de Godoy, jurado y vecino de la ciudad, en representación del resto de jurados, hizo llegar a la Corona el gran daño que ocasionaba a las gentes pobres de Córdoba pagar 2 mrs. por cada vela, más otros 2 mrs. por prenda. Pero el dato más importante es la referencia acerca del pago de entre 15 o 20 mrs. por cada casa:

(...) Juan Peres de Godoy, jurado e veçino desta çibdad, por sy e en nombre de los otros jurados della, nos fyso relaçion de los daños que habian resçibido e resçiben las gentes pobres desta dicha çibdad en pagar dos maravedis de las velas que pagan, e que por ello, diz que les llevan otros cada dos maravedís de costas, e que por cada quatro maravedís diz que les llevan prendas de lo que tienen por casa, que valen fasta quinze o veynte maravedís, poco más o menos, en lo qual dis que resciben mucho agravio e daño (... $)^{187}$

Gracias a los datos ofrecidos por este documento podemos confirmar que desde 1452 hasta 1500 se mantenía el mismo gravamen sobre los pobres a pesar de las continuas quejas que eran realizadas y presentadas a la Corona, es decir, $2 \mathrm{mrs}$. por cada vela. Igualmente, las prendas que se realizaban permanecían sin cambio alguno. Sin embargo, la mención a 15 o $20 \mathrm{mrs}$. por casa es fundamental para confirmar que no todos los concejos bajomedievales contaban únicamente con velas de carácter defensivo a través de vigilancias o guardas, sino también de otra tipología.

La decisión final de los Reyes Católicos fue aceptar las súplicas suprimiendo las prendas de 2 mrs., no obstante, también pidieron explicaciones al concejo de

186. 1497.01.11, AGS, RGS, f. 85r-v.

187. 1500.02.11, AMCO, J-1, doc. 77, f. 1 r. 
Córdoba sobre cómo y por qué se llevaban las velas de los vecinos de la ciudad. Esto era el principio del fin de esta renta, pues los ingresos que el concejo cordobés obtenía de ella desde 1452 a 1479 descendieron notablemente. Esta medida encabezó la eliminación de la renta, ya que para 1503 aparecen las últimas referencias sobre ella ${ }^{188}$, concretamente en el cabildo del 10 de julio de dicho año, momento en el que se decide su supresión por el daño que causaba al pueblo:

\begin{abstract}
(...) Estos señores platicaron sobre las velas que se cojen en Córdoua e en su tierra, e del agrauio que rescibe el pueblo, e de cómo se fabló que de tres o quatro meses ha en ello para que se quitasen, e agora pues que es viniendo el día de Sant Juan, cuando ellas se arriendan, mandó la cibdad que no aya velas, nin se arrienden en esta cibdad ni en su tierra (... $)^{189}$.
\end{abstract}

Finalmente, se ordenó que nadie pagase por las velas, dejando libre del pago al arrendador de las mismas, que para esta fecha era Fernando de Baeza. Por lo tanto, teniendo en cuenta los datos obtenidos de las fuentes bajomedievales las velas no se entienden como una renta concejil más inserta en el campo militar, sino que se trataría de un pago al que eran obligados todos los vecinos de la ciudad de Córdoba y su tierra para permitirles alumbrar con velas de cera, llegando a gravar la iluminación de sus propias viviendas.

\title{
3. Conclusiones
}

En el presente estudio he analizado los diferentes ingresos de los que disponía la hacienda cordobesa para el siglo XV. Gracias a la relación de cuentas del concejo cordobés de 1452-1453, completado con datos extraídos del Registro General del Sello, Archivo Municipal de Córdoba, Archivo de la Catedral de Córdoba y de los Protocolos Notariales del Archivo Histórico Provincial de Córdoba, he conseguido llevar a cabo un análisis detallado sobre los ingresos que engrosaban las arcas concejiles cordobesas y sobre las diversas rentas que eran aplicadas a los vecinos tanto de la ciudad como de su alfoz. En Córdoba, al igual que ocurría en otras haciendas concejiles, las autoridades municipales impusieron cada vez más gravámenes recaudatorios en el transcurso de los siglos XIV y XV con motivo de la búsqueda de recursos para sanear la economía concejil y hacer frente a los gastos comprometidos.

De todos los ingresos que obtuvo el concejo de Córdoba entre 1452 y 1453, las transacciones comerciales y los impuestos de circulación reportaron el mayor beneficio. El almojarifazgo y la roda son las rentas de mayor importancia y volumen y hay que tener en cuenta que no se contabilizan para los citados años el portazgo y las castillerías. Si añadimos estas dos últimas, la cifra de ganancias aumentaría

188. J. Edwards. Christian Córdoba. The city and its región in the late Middle Ages, Cambridge, 1982, p.83.

189. 1503.07.10, AMCO, LAC, f. 78r.

HID 41 (2014) 275-319 
notablemente. Que el almojarifazgo sea tan importante para Córdoba no puede sorprendernos, al igual que en Sevilla, pues ambos concejos gozaban del almojarifazgo de las villas de su tierra de manera que el cobro de esta renta se aplicaba a toda la jurisdicción del reino y duplicaba los beneficios. Los pasajes de El Guijo y Moratilla aportaban unas cifras muy inferiores, aún así siempre solían ir unidas a la asadura, montazgo u otras rentas pecuarias puesto que la circulación de los ganaderos por estos lugares provocaba que tuvieran que abonar todos estos pagos en conjunto. No obstante, los beneficios de estos pasajes debían ser muy superiores, al menos así aparece en 1494 cuando Alfonso Ramírez de Baeza como arrendador de la renta del pasaje del Guijo y la roda pagó 180.057 mrs.

El segundo bloque de rentas concejiles estaba integrado por las que hemos denominado otras rentas concejiles, ya que su tipología obliga a separarlas del resto de los grandes grupos de impuestos existentes. El grueso de estas rentas proviene de multas y penas que el concejo imponía a todos los vecinos, oficiales, e incluso forasteros, que quebrantaban de un modo u otro las ordenanzas de la ciudad. La renta de las velas es la siguiente que ingresaba más dinero, aunque al fin y al cabo podría considerarse como otra pena más según las prendas que eran llevadas a cabo a los pobres exigiéndoles el pago de $2 \mathrm{mrs}$. De alguna manera, este impuesto puede ser entendido como un antecesor del pago que efectuamos sobre la red eléctrica para conseguir luz diariamente. Por su parte, las aljamas también contribuyen de forma notable, ocupando el tercer lugar la de los moros que pagaban tanto el pecho como el derecho sobre la carne. Finalmente los aguadores y la meaja de los paños, eran las que aportaban cantidades menores, aunque probablemente en el caso de la segunda renta las cifras fuesen superiores a lo largo del siglo XV pues ya vimos que en 1490 Juan de Cea obtuvo en pública almoneda este renta por $10.000 \mathrm{mrs}$.

Respecto al último grupo de rentas, ni que decir tiene que son el grueso de todos los concejos. Sorprendentemente en la relación de cuentas que se presenta en 1452 Córdoba no consigue grandes ingresos de su tierra, o al menos el mayor beneficio, a pesar de ser una ciudad con buenas heredades de cereal. De todos los bienes raíces, las dehesas aportaron mayores ingresos, mejorados con herbajes, hazas y terrazgos. Las pesquerías también contribuyeron con importantes sumas de dinero aunque no se refleje en el documento anexo a este estudio. A través de la documentación de finales del XV se observa la existencia de muchas pesquerías y los beneficios que reportaban tanto a particulares, que las tenían en arrendamiento, como a la ciudad. Para acabar, los bienes inmuebles también dieron ganancias, donde hornos de pan, casas industriales, como las de los Tintes o de la Red, casillas y fuentes, eran las propiedades que dejaron dinero al concejo de Córdoba en 1452. Evidentemente gozaban de otros bienes inmuebles, pero no todos los años quedaban vacantes o se recaudaban los mismos.

En definitiva, el concejo de Córdoba consiguió 261.605 mrs. de ingresos para su hacienda del año que va de 1452 al de 1453 . Es evidente la necesidad de conocer otras relaciones de cuentas que nos permita saber con firmeza el desarrollo y la evolución de la economía concejil cordobesa, indagar sobre qué rentas perma- 
necían más tiempo, si los ingresos variaban en demasía, o por el contrario, mantenían el mismo nivel, si acontecían ingresos extraordinarios, si los gastos eran superiores, y por ende, se encontraban en un estado de déficit, entre otros muchos aspectos. Aún así, con este trabajo he pretendido aportar un estudio más acerca de la economía bajomedieval andaluza, profundizando en la hacienda cordobesa, que se presenta hasta nuestro días exenta de una análisis exclusivo, que a su vez nos permita conocer no sólo las rentas de las que vivía, sino también el funcionamiento del concejo en materia económica, completando así el conocimiento de la historia bajomedieval cordobesa.

\section{APÉNDICE DOCUMENTAL ${ }^{190}$}

1453.08.31, Córdoba.

Relación de las rentas del concejo de Córdoba desde 1452 a 1453.

\section{AMCO, C-1036, doc.14, ff. 352r-357r.}

f. 352r. (...) es esta copia e relaçion de escriptura de los dichos años pasados e presente, e los presçios en que la dichas rentas estuvieron e están, e los maravedís que por carta de mandamiento de Córdova fueron librados este año e el dicho año pasado, segund lo saque de los dichos sus libros de las dichas // f. 352v. rentas, uno en pos de otro, es esto que se sygue [es] relaçión del año pasado que se cunplió por el día de Sant Juan de junio que pasó deste presente año de çinquenta e tres, e en fin de cada uno va firmado:

\section{RENTAS}

Por el almojarifadgo de Almódovar del Río con las ventas de Sant Andrés e Guadarromán se arrendó el dicho año pasado, ante my, da el dicho recabdador en copia que valió el dicho año ochoçientos maravedís.

Por el almojarifadgo de las Posadas, valió el dicho año dos myll e nueveçientos e dos maravedís e çinco ducados.

Por el almojarifadgo de Peñaflor, valió el dicho año myll e sieteçientos.

Por el forno de Peñaflor dize que valió çient maravedís.

Por los derechos de Moratylla con el pasaje de ambos los ríos syn la defesa myll e trezientos e quarenta e syete maravedís.

Por el almojarifadgo de Fornachuelos, tres myll e çiento e veynte e çinco maravedís.

Por el almojarifadgo de Villar no se arrendó el dicho año pasado.

Por el almojarifadgo de Belmez e Espiel e Nava de Ovejo e el Allozar no se arrendó el dicho año pasado por cabsa de la ocupaçión que tiene fecha dél con las villas de Córdova el maestre de Alcántara. // f. 353r.

Por el almojarifadgo de la Fuente Ovejuna tres myll e dozientos e veynte e çinco maravedís.

190. Solamente se ha incluido la transcripción de la parte de ingresos para este estudio. 
Por los fornos de dicho lugar de pan cozer, dize el dicho recabdador quel uno valió quatroçientos maravedís, e el otro ocupó el maestre.

Por el almojarifadgo de la villa de Pedroche valió çinco myll e fonze maravedís.

Por el almojarifadgo de Ovejo valió çinquenta maravedís.

Por el almojarifadgo de la puente de Alcolea valió otros çinquenta maravedís.

Por el almojarifadgo de Adamuz e Algallarín, tres myll e quinientos e quarenta e siete maravedís.

Por el almojarifadgo de Pedro Abad dozientos maravedís.

Por el almojarifadgo de Montoro diez myll e ochoçientos e veynte e quatro maravedís.

Por el almojarifadgo de Aldea del Rio myll e seysçientos e doze maravedís.

Por el almojarifadgo de Bujalance treze myll maravedís.

Por el forno de Bujalance, está a sensal por sesenta maravedís cada año.

Por un solar que solía ser forno de dicho lugar, está çinco maravedís a sensal de cada año.

Por el almojarifadgo de Castro del Rio e Castro el Viejo catorze myll e quinientos maravedís.

Por la renta del carbón de fumo, tómola el dicho año Gomes Fernández de Santo Eufemia, arrendador en diez myll e seysçientos e çinco maravedís en pago de carta debda que Córdova le devía.

Por el almojarifadgo de Santaella quatro myll maravedís.

Por el almojarifadgo de La Ranbla diez e syete myll e quinientos.

Por el almojarifadgo de pan cozer del dicho lugar, está en presçio de ochoçientos maravedís. // f. 353v.

Por el forno de pan cozer de Santaella, está en presçio de veynte maravedís.

Por el yerbaje de Santaella trezientos e setenta e tres maravedís.

Por la yerba de la defesa de La Parrilla, tómola el dicho año Gonzalo Carryllo, veynte e quatro, arrendador en presçio de seys myll maravedís.

Por la roda de Aluacar con amos los camynos, veynte e un myll e dozientos e quarenta e seys maravedís.

Por la defesa de Los Enjeneros tres myll e seysçientos e quarenta e ocho maravedís.

Por los descargos de las tierras vacadas del término de Córdova, de aquen del rio de Guadalquivir syn Fornachuelos, los myll e ochoçientos e noventa e çinco maravedís.

Por el yerbaje del rio ayuso dozientos e çinquenta maravedís.

Por la mitad de la defesa de Villalobyllos, que pertenesçe a los propios, çinco myll e trezientos e treynta e tres maravedís.

Por las velas del cuerpo de la çibdad nueve myll e ochoçientos maravedís.

Por las velas del rio arriba dos myll e quarenta e dos maravedís.

Por las velas del rio ayuso myll e seysçientos maravedís.

Por de las velas de Pedroche estovieron las de Fuente Ovejuna en sieteçientos maravedís.

Por las otras velas de Pedroche en trezientos maravedís. // f. 354r.

Por la defesa de Moratylla seteçientos e çinquenta maravedís.

Por la defesa de Algallarín, tóvola el dicho año arrendada de Córdova al jurado Gonzalo Ruis de Martín Cabrera, en presçio de myll e quinientos maravedís.

Por la defesa de Madroñiz e El Finojoso e Torrecatalina, estas dichas rentas son de los dichos propios, [e] estuvieron e están ocupadas por el dicho maestre de Alcántara con las dichas villas este dicho año; al tienpo que Cordova envió el pendón a se restituyr en ellas, dicho fue al dicho recabdador de los propios e por mandado de Córdova como a çiertos 
arrendadores que tenían arrendadas las dichas defesas de dicho maestre el dicho año, treynta e ocho myll e ochoçientos e treynta maravedís.

Por las penas calonias de los corredores que llenan mas derecho de seys maravedís al millar, se arrendaron por fonze myll maravedís.

Por la renta de las penas de los que pasan las fordenanzas de Córdova, valió e arrendose esta dicha renta en presçio de quarenta e seys myll maravedís por un año.

Por la renta de los aguadores myll e syeteçientos maravedís.

Por la meaja del medir de los lienços e sayales çient maravedís. // f. 354v.

Por a çensual de la dicha çibdad, que son sus propios, el derecho de la carne de los moros tiénelo el aljama de los dichos moros por myll maravedís cada año.

Por la cabeza del pecho de los moros rentan de cada año seys myll maravedís.

Por las casas tinte de adoana tyénelas Pero Días de Xerez e Jayme Martín, tyntorero, cada uno dellos la mitad por presçio de treze doblas castellanas.

Por las casas de la Corredera de que es arrendador Juan Rodrigues, odrero, por presçio de nueve doblas castellanas.

Por las casas otras de la Corredera, de que es arrendador el dicho Juan Rodrigues, por otras nueve doblas castellanas.

Por las casas de la Red están en quatro doblas castellanas.

Que son todo treynta e çinco doblas castellanas con todas a rasón de çiento e çinquenta maravedís, montan çinco myll e dozientos e çinquenta maravedís.

Por la faça de los Barreros, tyénela a sensual Luys Mexia, en presçio de veynte maravedís cada año.

Por el molino de Gaete, tiénelo a sensual Martín Alonso, vesyno del dicho lugar, en diez maravedís cada año el qual diz que ocupa el dicho maestre. // f. 355 r.

Por la casylla de la Fuente de Sant Pablo, tyenela a sensual Alonso Méndez en otros diez maravedís.

Por la faça e pesquyria del arroyo de la Cabrilla, está a sensual en otros diez maravedís.

Por la tierra de Córdova que defesó el conçejo de Torremilano con sus ganados, a de dar a censo cada año diez maravedis, e diz que está ocupado por el comendador Gonzalo Mexía.

Por la faça que está a las ollerías de la puerta de Colodro, tyénela a sensual Pedro Tafur, alguacil, por diez maravedís cada año, e dizen que lo lleva la del alcalde García Fernándes e no Córdova.

Asy que montan las dichas rentas de los dichos propyos de dicho año de çinquenta e dos que va a çinquenta e tres años, de que se faze cargo al dicho recabdador Juan Rodrigues de Baeça en la manera que dicha es, dozientos e sesenta e quatro maravedís e ochoçientos e treynta e çinco maravedís. 
Cuadro 1. Almojarifazgo de Córdoba

\begin{tabular}{|c|c|c|}
\hline \multicolumn{3}{|c|}{ CIFRAS DE INGRESOS POR ALMOJARIFAZGO } \\
EN LA CIUDAD DE CÓRDOBA \\
\hline PERIODO DE ARRENDAMIENTO & MONEDA EN MARAVEDÍs & $\begin{array}{c}\text { MONEDA EN DOBLAS DE } \\
\text { BANDA }\end{array}$ \\
\hline $1428-1433$ & 271.906 & 2.700 \\
\hline $1440-1443$ & 441.283 & 4.400 \\
\hline $1444-1445$ & 882.566 & 8.800 \\
\hline $1448-1450$ & 752.669 & 7.500 \\
\hline $1455-1458$ & 1.266 .666 & 8.400 \\
\hline $1459-1462$ & 1.274 .583 & 8.420 \\
\hline $1463-1467$ & 1.553 .466 & 7.750 \\
\hline $1480-1482$ & 1.625 .000 & 4.450 \\
\hline 1483 & 1.275 .000 & 3.500 \\
\hline $1484-1487$ & 1.111 .111 & 3.400 \\
\hline $1488-1491$ & 1.205 .500 & 3.460 \\
\hline $1493-1494$ & 1.185 .000 & 3.450 \\
\hline $1495-1497$ & 1.200 .000 & 3.455 \\
\hline $1498-1499$ & 1.100 .000 & 3.390 \\
\hline $1501-1502$ & 1.258 .000 & 3.475 \\
\hline & & \\
\hline & & \\
\hline
\end{tabular}

(Fuente: Ladero Quesada, M.A., La hacienda real..., pp. 129-130.) 
Cuadro 2. Ingresos de la hacienda de Córdoba para mediados del siglo XV ${ }^{191}$

\begin{tabular}{|c|c|c|c|}
\hline \multicolumn{4}{|c|}{ CÓRDOBA (1452-1453) } \\
\hline Tipos de rentas & Desglose de rentas & $\begin{array}{l}\text { Moneda en } \\
\text { maravedís }\end{array}$ & $\begin{array}{l}\text { Recuento } \\
\text { total en } \\
\text { maravedís }\end{array}$ \\
\hline \multirow{3}{*}{$\begin{array}{c}\text { Impuestos indirectos: } \\
\text { Transacciones comerciales } \\
\text { y de circulación }\end{array}$} & Almojarifazgo & 83.681 & \multirow{3}{*}{106.274} \\
\hline & Roda & 21.246 & \\
\hline & Pasaje de moratilla & 1.347 & \\
\hline \multirow{6}{*}{$\begin{array}{l}\text { Procedentes de Bienes } \\
\text { raíces }\end{array}$} & Herbajes & 6.623 & \multirow{6}{*}{75.089} \\
\hline & Dehesas & 50.071 & \\
\hline & $\begin{array}{l}\text { Terrazgos (Incluye la renta del } \\
\text { carbón de humo) }\end{array}$ & 12.500 & \\
\hline & Hazas & 30 & \\
\hline & Pesquerías & 10 & \\
\hline & $\begin{array}{l}\text { Bienes Inmuebles (Casas, } \\
\text { Hornos, Molino y Casilla) }\end{array}$ & 5.855 & \\
\hline \multirow{5}{*}{ Otras rentas concejiles } & Multas & 57.000 & \multirow{5}{*}{80.242} \\
\hline & Comunidades étnico-religiosas & 7.000 & \\
\hline & Aguadores & 1.700 & \\
\hline & $\begin{array}{l}\text { La meaja del medir de los } \\
\text { paños }\end{array}$ & 100 & \\
\hline & Las velas & 14.442 & \\
\hline & \multicolumn{2}{|l|}{ Ingresos totales } & 61.605 \\
\hline
\end{tabular}

(Fuente: Elaboración propia del autor.)

\section{BibliogRAFÍA}

Abboud Haggar, Soha. "Leyes musulmanas y fiscalidad mudéjar", Actas del V Congreso de Estudios Medievales. Finanzas y fiscalidad municipal, León, 1997, pp. 169-205.

Asenjo González, María. Segovia. La ciudad y su tierra a fines del Medievo, Segovia, 1986, p. 457.

191. En el apartado de Hazas, se ha descontado aquella que estaba ubicada en el arroyo de la Cabrilla para incluirla en pesquerías, ya que en el documento, aparecen ambas propiedades en una sola, pagando por ellas un total de $10 \mathrm{mrs}$. anuales. 
Ayllón Gutiérrez, Carlos. "Sobre los orígenes medievales de La Roda: a propósito de una reciente reedición bibliográfica", Al-Basit: Revista de Estudios Albatecenses, 37 (1995), pp. 37-44.

Bonachía Hernando, Juan Antonio. "El concejo como señorío (Castilla, siglos XIII-XV)", Actas del II Congreso de Estudios Medievales. Concejos y ciudades en la Edad Media hispánica, Móstoles, 1990, pp. 429-463.

Borrero Fernández, Mercedes. "Las haciendas de los concejos rurales sevillanos", Actas del II Coloquio de Historia Medieval Andaluz. Hacienda y comercio, Sevilla, 1981, pp. 67-79.

Cabrera Muñoz, Emilio. "El problema de la tierra en Córdoba a mediados del siglo XIV”, Cuadernos de Estudios Medievales, IV-V (1979), pp. 41-71.

Cantera Montenegro, Santiago. "Los usos del agua en las cartujas de la corona de Castilla, en la transición del medievo al renacimiento", en Clemente Ramos, Julián (Ed.). El medio natural en la España Medieval: Actas del I congreso sobre Ecohistoria e Historia Medieval, pp. 257-275.

Carmona Ruiz, María Antonia. La ganadería en el reino de Sevilla durante la Baja Edad Media, Sevilla, 1998, pp. 429.

Carrasco Pérez, Juan. "Sobre la hacienda municipal de Tudela a fines de la Edad Media (1480-1521)", en Historia de la Hacienda española:(épocas antigua y medieval): Homenaje a Luis García de Valdeavellano, Ministerio de Hacienda, Instituto de Estudios Fiscales, 1982, pp. 127-169.

—. "La hacienda municipal de Tudela a fines de la Edad Media (1480-1521)", En la España Medieval, 7 (1985), pp. 1663-1700.

Castro Antolín, Mariano L. de. "Consideraciones en torno al origen y concepto del almojarifazgo", Actas del I Congreso de Historia de Andalucía. Andalucía Medieval, vol. I, Córdoba, 1982, pp. 435-442.

Collantes de Terán Sánchez, Antonio. "Ciudades y fiscalidad", VI Coloquio Internacional de Historia Medieval de Andalucía. Las ciudades andaluzas (Siglos XIII-XVI), Málaga, 1991, pp. 129-149.

— y Menjot, Denis. "La génesis de la fiscalidad municipal en Castilla: primeros enfoques", Revista d'Historia Medieval, 7 (1996), Valencia, pp. 53-80.

- y Menjot, Denis. "Hacienda y fiscalidad concejiles en la corona de Castilla en la Edad Media”, Historia. Instituciones. Documentos, 23 (1996), pp. 213-254.

—. "Ciudades y villas andaluzas: variedad impositiva y diversidad ante el hecho fiscal”, Actas del V Congreso de Estudios Medievales. Finanzas y fiscalidad municipal, León, 1997, pp. 485-506.

Córdoba de la Llave, Ricardo. La industria medieval de Córdoba, Córdoba, 1990, pp. 223-225.

-. "Comunicaciones, transportes y albergues en el reino de Córdoba a fines de la Edad Media”, Historia. Instituciones. Documentos, 22 (1995), Sevilla, pp. $87-118$.

—. "Navegación y transporte fluvial en la Península Ibérica a fines de la Edad Media", en Criado de Val, Manuel (Coord.). Actas del III Congreso Internacional de Caminería Hispánica, Madrid, Aache Ediciones, 1997, pp. 215-233. 
Edwards, John. "Las peculiaridades económicas de la Andalucía Bajomedieval: el caso de Córdoba", Actas del II Coloquio de Historia Medieval Andaluza. Hacienda y comercio, Sevilla, 1981, pp. 125-131.

- Christian Córdoba. The city and its región in the late Middle Ages, Cambridge, 1982, pp. 81-198.

-. "El comercio lanero en Córdoba bajo los Reyes Católicos", Actas del I Congreso de Historia de Andalucía. Andalucía Medieval, vol. I, Córdoba, 1982, pp.423-428.

Escobar Camacho, José Manuel. "Economía urbana de Córdoba durante la época de los RR.CC", en Córdoba y la época de Isabel la Católica, Córdoba: Real Academia de Córdoba de Ciencias, Bellas Letras y Nobles Artes, 2006, pp. 193-216.

Falcón Pérez, María Isabel. "Finanzas y fiscalidad de ciudades, villas y comunidades de aldeas aragonesas", Actas del V Congreso de Estudios Medievales. Finanzas y fiscalidad municipal, León, 1997, pp. 241-273.

Francisco Olmos, José María de. "La moneda de la Castilla bajomedieval. Medio de propaganda e instrumento económico", II Jornadas científicas sobre documentación de la Corona de Castilla (siglos XIII-XV), Madrid, 2003, pp. 277-345.

Galán Sánchez, Ángel, "Hacienda y fiscalidad en el reino de Granada: algunas razones para su estudio", Chronica nova: Revista de historia moderna de la Universidad de Granada, 31 (2005), pp. 11-22.

- y Peinado Santaella, Rafael Gerardo. "De la madina musulmana al concejo mudéjar: fiscalidad regia y fiscalidad concejil en la ciudad de Granada tras la conquista castellana", en Sánchez Martínez, Manuel y Menjot, Denis (Coords.), Fiscalidad de Estado y fiscalidad municipal en los reinos hispánicos medievales, Casa Velázquez, 2006, pp. 197-238.

—. "Poder y fiscalidad en el reino de Granada tras su conquista: algunas reflexiones", Studia Histórica. Historia Medieval, 30 (2012), pp. 67-98.

Gil García, María del Pilar. "Portazgo y almotacenazgo en La Roda de Albacete a fines de la Edad Media", Congreso de Historia del Señorío de Villena, Instituto de Estudios Albacetenses, Albacete, 1987, pp. 219-225.

González, María Estela. "La anubda y la arrobda en Castilla", Cuadernos de Historia de España, XXXIX-XL (1964), Buenos Aires, pp. 5-42.

González Arce, José Damián. "El almojarifazgo de Sevilla: una renta feudal”, VI Coloquio Internacional de Historia Medieval de Andalucía. Las ciudades andaluzas (Siglos XIII-XVI), Málaga, 1991, pp.151-159.

—. "La política fiscal de Alfonso X en el reino de Murcia: portazgos y diezmos", Studia histórica. Historia Medieval, 10 (1992), pp. 73-100.

—. "Documentos sobre el almojarifazgo de Sevilla (siglos XIII-XIV)", Historia. Instituciones. Documentos, 20 (1993), Sevilla, pp. 165-196.

—. "Las rentas del almojarifazgo de Sevilla", Studia Histórica. Historia Medieval, 15 (1997), Salamanca, pp. 209-254. 
—. La fiscalidad del señorío de Villena en la Baja Edad Media, Albacete, 2002, pp. 128-330.

—. "La fiscalidad agraria en el señorío de Villena en la Baja Edad Media", en Vallejo Pousada, Rafael, Furió Diego, Antoni (Coords.), Los tributos de la tierra: fiscalidad y agricultura en España: (siglos XII-XX), 2008, pp. 103-136.

—. "De conjunto de rentas a impuesto aduanero. La transformación del almojarifazgo durante el siglo XIV en el reino de Murcia", Anuario de Estudios Medievales, 42 (2012), pp. 669-696. http://dx.doi.org/10.3989/aem.2012.42.2.14

González Jiménez, Manuel. El concejo de Carmona a fines de la Edad Media (1464-1523), Sevilla, 1973, pp. 190-225.

—. "Ordenanzas del concejo de Córdoba (1435)", Historia. Instituciones. Documentos, 2 (1975), Sevilla, pp. 191-315.

- "Fiscalidad regia y señorial entre los mudéjares andaluces (siglos XIIIXV)", Actas del V Simposio Internacional de Mudejarismo, Teruel, 1991, pp. 221-240.

-. "Aranceles cordobeses de portazgo. Aportación al vocabulario del comercio medieval", en González Jiménez, Manuel. A través de Sevilla y Andalucía. Estampas de historia medieval, Universidad de Sevilla, 2011, pp. 113-125.

González Mínguez, César. El portazgo en la Edad Media: Aproximación a su estudio en la corona de Castilla, Universidad del País Vasco, 1989, pp. 93-105.

Guerrero Navarrete, Yolanda y Sánchez Benito, José María, Cuenca en la Baja Edad Media: un sistema de poder urbano, Diputación Provincial de Cuenca, Cuenca, 1994.

-. "Impuestos y contribuyentes en los concejos de la Meseta Norte", Actas del $V$ Congreso de Estudios Medievales. Finanzas y fiscalidad municipal, León, 1997, pp. 353-394.

Hernández Íñigo, Pilar. "La pesca fluvial y el consumo de pescado en Córdoba (1450-1525)", Anuario de Estudios Medievales, $27 / 2$ (1997), pp. 1045-1116. http://dx.doi.org/10.3989/aem.1997.v27.i2.632

Izquierdo Benito, Ricardo. "El aprovechamiento del medio natural en el reino de Toledo durante los siglos bajomedievales", en Clemente Ramos, Julián (Ed.). El medio natural en la España Medieval: Actas del I congreso sobre Ecohistoria e Historia Medieval, Cáceres, 2001, pp. 163-193.

Jara Fuente, José Antonio. "Identidad corporativa y constitución política urbana. Solidaridades económicas y poder en el marco de los procesos de afianzamiento de las rentas concejiles", en Guerrero Navarro, Yolanda et alii. Fiscalidad, sociedad y poder en las ciudades castellanas en la Baja Edad Media, Universidad autónoma de Madrid, 2006, pp. 11-60.

Klein, Julius. La Mesta. Estudio de la historia económica española, 1273-1836, Madrid, 1990, pp. 444-447.

Ladero Quesada, Miguel Ángel. La Hacienda real de Castilla en el siglo XV, Madrid, Universidad de la Laguna, 1973, pp. 125-219.

_. El siglo XV en Castilla, Barcelona, 1982, pp. 17-25. 
-. "Las transformaciones de la fiscalidad regia castellano-leonesa en la segunda mitad del siglo XIII (1252-1312)", en Historia de la Hacienda española: (épocas antigua y medieval): Homenaje a Luis García de Valdeavellano, Ministerio de Hacienda, Instituto de Estudios Fiscales, 1982, pp. 323-406.

- "Producción y renta cerealeras en el reino de Córdoba a finales del siglo XV”, Actas del I Congreso de Historia de Andalucía, vol. I, Córdoba, 1982, pp. 375-396.

—. "Las haciendas concejiles en la corona de Castilla", Actas del V Congreso de Estudios Medievales. Finanzas y fiscalidad municipal, León, 1997, pp. 8-71.

—. "Estructuras y políticas fiscales en la baja Edad Media", Edad Media. Revista de Historia, 2 (1999), Universidad de Valladolid, pp. 113-150.

López Rider, Javier. Estudio sobre construcciones hidráulicas e industriales de Santaella (Córdoba), Diputación de Córdoba, Córdoba, 2013, pp. 134-135.

—. "La producción de carbón en el reino de Córdoba a fines de la Edad Media: un ejemplo de aprovechamiento del monte mediterráneo" (en prensa).

López Villalba, José Miguel. "Política local y abastecimiento urbano: el pescado de Guadalajara en la Baja Edad Media", Studia Histórica. Historia Medieval, 25 (2007), pp. 221-234.

Mackay, Angus y Ladero Quesada, Miguel Ángel. Moneda, precios y política en la Castilla del siglo XV, Universidad de Granada y Universidad de Sevilla, 2006, pp. 182-183.

Mazo Romero, Fernando. "Tensiones sociales en el municipio cordobés en la primera mitad del siglo XV", Actas del I Congreso de Historia de Andalucía. Andalucía Medieval, vol. II, Córdoba, 1982, pp. 85-112.

Mitre Fernández, Emilio. "Córdoba y su campiña. Una comarca fronteriza al comienzo del siglo XV”, Cuadernos de Estudios Medievales, I (1973), pp. 9-33.

Palacios Martín, Bonifacio y Falcón Pérez, María Isabel. "Las haciendas municipales de Zaragoza, a mediados del siglo XV (1440-1472)", en Historia de la Hacienda española: (épocas antigua y medieval): Homenaje a Luis García de Valdeavellano, Ministerio de Hacienda, Instituto de Estudios Fiscales, 1982, pp. 539-606.

Peinado Santaella, Rafael Gerardo. "Fiscalidad señorial y tráfico comercial en Andalucía a fines de la Edad Media: Notas para su estudio", Actas del II Coloquio de Historia Medieval Andaluza. Hacienda y comercio, Sevilla, 1981, pp. 133158.

Pino García, José Luis del y Rojas, Eva. "Infraestructura viaria y pontonera medieval en torno al Bembézar”, Estudios de Historia y Arqueologia Medievales, XI (1996), pp. 365-415.

Quintanilla Raso, María Concepción. "Notas sobre el comercio urbano en Córdoba durante la Baja Edad Media”, Actas del I Congreso de Historia de Andalucía. Andalucía Medieval, vol. I, Córdoba, 1982, pp. 413-423.

Ríos Rodríguez, María Luz. "Apropiación y organización social de un medio natural: pesca fluvial y pesqueras en la Galicia medieval", en Mundos medieva- 
les, espacio, sociedades y poder: homenaje al profesor José Ángel García de Cortázar y Ruiz de Aguirre, Universidad de Cantabria, 2012, pp. 1827-1842.

Rodríguez Molina, José. "Algunos datos sobre la actividad comercial y fiscal en Jaén y Baeza a fines del siglo XV", Actas del II Coloquio de Historia Medieval Andaluza. Hacienda y comercio, Sevilla, 1981, pp. 159-176.

Sánchez Benito, José María. "Las haciendas de los concejos en la Submeseta sur", Actas del V Congreso de Estudios Medievales. Finanzas y fiscalidad municipal, León, 1997, pp. 395-430.

Sánchez Rubio, María de los Ángeles. El concejo de Trujillo y su alfoz en el tránsito de la Edad Media a la Edad Moderna, Universidad de Extremadura, 1993, pp. 165-215.

Santiago Haro, José. "Sobre el trayecto de la «Vía Augusta» por los actuales términos de Andújar, Marmolejo y Lopera (Jaén): Una nueva propuesta (II)", Boletín del Instituto de Estudios Giennenses, 199 (2009), pp. 11-56.

Sarasa Sánchez, Esteban. “Concejos y ciudades medievales en el reino de Aragón. Hacia una tipología socioeconómica de los municipios aragoneses en la Edad Media: De la foralidad a la municipalidad", Actas del II Congreso de Estudios Medievales. Concejos y ciudades en la Edad Media hispánica, Móstoles, 1990, pp. 73-122.

Torres Fontes, Juan. "Puerto de La Losilla: portazgo, torre y arancel”, Miscelánea Medieval Murciana, IX (1982), pp. 57-85.

Veas Arteseros, María del Carmen. Fiscalidad concejil en la Murcia de fines del medievo, Universidad de Murcia, 1991, pp. 78-183.

Fecha de recepción del artículo: febrero de 2014

Fecha de aceptación y versión final: julio de 2014 
